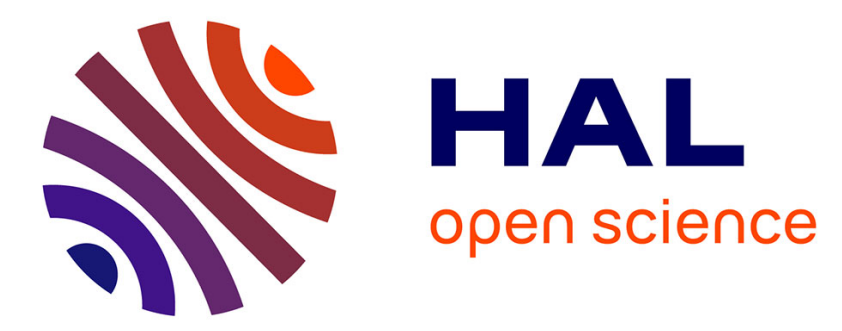

\title{
Formability prediction using bifurcation criteria and GTN damage model
}

\author{
Muhammad Waqar Nasir, Hocine Chalal, Farid Abed-Meraim
}

\section{To cite this version:}

Muhammad Waqar Nasir, Hocine Chalal, Farid Abed-Meraim. Formability prediction using bifurcation criteria and GTN damage model. International Journal of Mechanical Sciences, 2021, 191, pp.106083. 10.1016/j.ijmecsci.2020.106083 . hal-03225596

\section{HAL Id: hal-03225596 \\ https://hal.science/hal-03225596}

Submitted on 12 May 2021

HAL is a multi-disciplinary open access archive for the deposit and dissemination of scientific research documents, whether they are published or not. The documents may come from teaching and research institutions in France or abroad, or from public or private research centers.
L'archive ouverte pluridisciplinaire HAL, est destinée au dépôt et à la diffusion de documents scientifiques de niveau recherche, publiés ou non, émanant des établissements d'enseignement et de recherche français ou étrangers, des laboratoires publics ou privés. 


\title{
Formability prediction using bifurcation criteria and GTN damage model
}

\author{
Muhammad Waqar Nasir ${ }^{1,2, \text { a) }}$ Hocine Chalal ${ }^{1, \text { b) }}$ Farid Abed-Meraim ${ }^{1, c)}$ \\ ${ }^{1}$ Laboratory LEM3, Université de Lorraine, CNRS, Arts et Métiers, F-57000 Metz, France. \\ ${ }^{2}$ Department of Mechanical Engineering, University of Engineering and Technology, Lahore 54000, \\ Pakistan. \\ a) muhammad_waqar.nasir@ensam.eu \\ b) hocine.chalal@ensam.eu \\ c) farid.abed-meraim@ensam.eu
}

\begin{abstract}
In this paper, four plastic instability criteria, which are based on the bifurcation theory, are coupled with the GTN damage model for the prediction of diffuse and localized necking. General bifurcation (GB) criterion and limit-point bifurcation (LPB) criterion are used to predict diffuse necking, while loss of ellipticity (LOE) criterion and loss of strong ellipticity (LOSE) criterion are used to predict localized necking. The resulting constitutive equations and instability criteria are implemented into the finite element code ABAQUS/Standard. The constitutive equations are formulated within the framework of large deformations and fully three-dimensional approach. Since the developed numerical tools have intended applications mainly for thin sheet metals; therefore, the plane-stress conditions are considered within the instability criteria. The present contribution focuses on the effect of destabilizing mechanisms, due to non-associative plasticity and non-normal plastic flow rule, on the prediction of forming limit diagrams (FLDs). Theoretical classification of the bifurcation criteria, in terms of their order of prediction of critical necking strains, is first presented. Then, several variants of the GTN model are combined with the bifurcation criteria for the prediction of FLDs for fictitious materials. It is shown that the hierarchical prediction order of the different instability criteria is consistent with the theoretical classification, for all the considered variants of the GTN model. More specifically, it is shown that the GB criterion provides a lower bound to all bifurcation criteria, in terms of necking prediction, while the LOE criterion represents an upper bound.
\end{abstract}

Keywords:

Bifurcation approach; Gurson-type model; Forming limit diagram; Ductile damage; Diffuse necking; Localized necking; Non-associative plasticity; Non-normal plastic flow. 


\section{Introduction}

Sheet metal forming is undoubtedly a manufacturing process that has massive applications in various areas, such as automotive, aerospace, home appliance and food industry. However, various defects may occur during forming processes, such as wrinkling, necking and fracture. These defects, which limit the formability of sheet metals, may be avoided by appropriately selecting the manufacturing process parameters and material characteristics. In this work, focus is confined to plastic instabilities that are inherent to the material, which are known to be responsible for limiting the sheet metal formability. These material plastic instabilities may include either diffuse or localized necking. Therefore, controlling such plastic instabilities results in enhanced productivity and high quality of products during the manufacturing process.

In order to characterize the formability of sheet metals, the concept of forming limit diagram (FLD) was first introduced by Keeler and Backofen [1], and later improved by Goodwin [2], which till date is widely used. The original procedure for the determination of FLD is based on experimental measurements, where metallic sheets of various geometries (covering different strain-path ratios, ranging from uniaxial tension to balanced biaxial tension) are deformed plastically with the help of a punch. The plot of the in-plane major and minor strains, which correspond to the onset of plastic strain localization, for the various sheet metal specimens, allows determining the forming limit diagram for the studied material. Various punch designs and sample geometries have been recommended in the literature (see, e.g., [3-5]). However, the experimental determination of FLDs is still very tedious and requires advanced equipment. Moreover, the experimental results are subject to lack of reproducibility. For these reasons, various theoretical and numerical approaches have been proposed in the literature for the FLD prediction. These approaches essentially require the combination of two key components, i.e., constitutive models and instability criteria. The constitutive models allow reproducing the essential physical phenomena that occur within the material for a specific loading condition. The instability criteria are coupled with the constitutive models to predict the occurrence of plastic instabilities (diffuse or localized necking in this work) for a given loading path.

Experiments have shown that when ductile materials undergo large plastic deformations, softening is observed prior to fracture, which causes the material to gradually lose its stress carrying capability. Therefore, the realistic representation of the mechanical behavior for ductile materials requires the coupling of elastic-plastic constitutive equations with damage theory. In this regard, two classes of damage theories have been developed in the literature over the last four decades. The first class, i.e. Continuum Damage Mechanics (CDM), treats the damage variable as the surface density of cracks, assumed to exist on the surface of a representative volume element (RVE) (see, e.g., [6-16]). Depending upon the anisotropy and softening behavior, the damage variable may be a scalar or a tensor quantity. The second class of damage theory is based on the micromechanical analysis of a porous material, which is represented by a void surrounded by a dense matrix inside an RVE. The damage variable in this case is the ratio 
of the void volume to the RVE volume. Gurson [17] first developed a micromechanics-based damage model by kinematic analysis of a spherical void present inside a spherical RVE. Gurson's model incorporates the effects of hydrostatic stresses and void growth. Subsequently, the Gurson model was extended by Tvergaard [18-20], Chu and Needleman [21] and Tvergaard and Needleman [22] in order to incorporate the effects of void nucleation, void coalescence, and void interaction parameters, in addition to void growth. The complete ductile damage model is commonly referred to as Gurson-Tvergaard-Needleman (GTN) damage model. Later, the GTN damage model was further extended for a wide variety of applications. For instance, extended versions of GTN damage model have been proposed in the literature, which are specific to oblate or prolate ellipsoidal voids [23-25] or generalized to non-spheroidal voids [26-29]. Shear modified extended Gurson models have also been developed for specific low stress triaxiality conditions (see, e.g., [30-34]). Dormieux and Kondo [35] and Morin et al. [36] presented their Gurson-based model, which considers the effects of initial void size. Moreover, a GTN-based layered model has been proposed by Lacroix et al. [37] and Morin et al. [38], which allows modeling advanced isotropic and kinematic hardening, while Gurson-like models have been developed for anisotropic matrix material in the work of Monchiet et al. [39] and Morin et al. [40].

To accurately model the plastic anisotropy of metallic materials, various phenomenological constitutive models have been developed in the literature in the recent decades. Hill [41] first proposed the quadratic yield function for anisotropic materials, as straightforward extension of the von Mises yield function. In order to enhance some anomalous behavior regarding material anisotropy, much effort has been made for the development of non-quadratic anisotropic yield functions (see, e.g., [42-48]). Most of these yield functions are based on the associative flow rule (AFR), in which the yield surface and the plastic potential function coincide. Unlike AFR, in the context of non-associative flow rule (NAFR), plastic flow is controlled by a specific potential function, which is different from the yield surface. Although AFR has been widely used for sheet metal forming applications, there are some theoretical [49-50] as well as experimental [51-54] evidences suggesting the non-applicability of AFR. With NAFR, it is possible to capture the directional yield stresses as well as the $r$-values (i.e., Lankford coefficients) simultaneously. For instance, in the work of Stoughton [55], Hill'48 quadratic yield function was implemented with NAFR, and accurate predictions of directional yield stresses and $r$-values were obtained. Furthermore, the predictive capabilities for anisotropy characteristics obtained from NAFR models in conjunction with quadratic yield functions have a level of accuracy similar to some advanced non-quadratic yield functions coupled with AFR (see Lian et al. [56]). Consequently, anisotropic plasticity models based on NAFR have recently been used by several researchers in the context of sheet metal forming (see, e.g., Lian et al. [56], Ghorbel et al. [57], Shen et al. [58], Tang et al. [59]).

For the prediction of plastic instabilities, a number of theoretical and numerical criteria have been developed in the literature. These criteria can be broadly classified in either diffuse or 
localized necking criteria. Considère [60] first proposed the maximum force criterion for the prediction of diffuse necking under uniaxial tension. Considère's criterion has been subsequently extended to in-plane biaxial loading by Swift [61]. Concurrently, Hill [62] proposed a localized necking criterion, which is based on bifurcation theory, also known as Hill's zero extension theory. Since Hill's criterion can only predict localized necking on the left-hand side of the FLD (i.e., from uniaxial tension to plane-strain tension), it has generally been used in conjunction with Swift's criterion to predict the complete FLD. Hora et al. [63] and Mattiasson et al. [64] extended Considère's and Swift's criteria in order to take into account strain-path changes in the prediction of localized necking. Marciniak and Kuczyński [65] developed another theoretical approach, commonly named as $\mathrm{M}-\mathrm{K}$ initial imperfection method, for the prediction of plastic instability based on the introduction of an initial imperfection. The $\mathrm{M}-\mathrm{K}$ initial imperfection method was further extended and improved by Hutchinson and Neale [66] and Yamamoto [67]. Hutchinson and Neale [66] extended the M K initial imperfection method by allowing the imperfection band rotation during plastic deformation. Analogously to the geometrie imperfection that was originally used in the M K initial imperfection method, Yamamoto [67] introduced an imperfection in the form of initial inhomogeneity in material properties. In contrast to the $\mathrm{M}-\mathrm{K}$ initial imperfection method, plastic instability theories based on bifurcation analysis have been developed over the past few decades. These theories predict the occurrence of plastic instabilities without the need for assuming arbitrary initial imperfection factors. Drucker [68] and later Hill [69] laid the foundations of general bifurcation theory for the prediction of diffuse necking. This theory requires the positiveness of the second-order work for non-bifurcation state. Later, Valanis [70] proposed the limit-point bifurcation theory for the prediction of diffuse necking. The latter occurs when the first Piola-Kirchhoff stress reaches a stationary value, which in turn requires the singularity of the elasto-plastic tangent modulus. On the basis of bifurcation theory, Rudnicki and Rice [71], Stören and Rice [72] and Rice [73] developed a plastic instability criterion for the prediction of localized necking in the form of a planar shear or necking band. This criterion for strain localization corresponds to the loss of ellipticity of the partial differential equations governing the associated boundary value problem. Then, Bigoni and Hueckel [74] and Neilsen and Schreyer [75] proposed a more conservative criterion for the prediction of flow localization, as compared to the loss of ellipticity criterion, namely loss of strong ellipticity criterion. Based on these bifurcation theories, closed form analytical solutions for limiting strains were also derived within the framework of small strains (see, e.g., [76-79]). It can be proved that within the framework of small strains and associative plasticity, general bifureation theory and loss of ellipticity criterion coincide with the limit point bifureation theory and loss of strong ellipticity criterion, respectively.

In the present contribution, elastic-plastic-damage constitutive equations are coupled with bifurcation-based instability criteria in the framework of large strains for the prediction of FLDs. More specifically, the GTN damage model is coupled with four instability criteria, namely, general bifurcation criterion (GB), limit-point bifurcation criterion (LPB), loss of strong ellipticity criterion (LOSE), and loss of ellipticity criterion (LOE). The latter is usually referred 
to as the Rice bifurcation criterion (Rice [73]). Similar methodologies have been followed by Mansouri et al. [80], Chalal and Abed-Meraim [81], and Bouktir et al. [82]. In the latter, CDM approach has been coupled with the four bifurcation-based instability criteria, whereas in the former two references, the GTN damage model has been coupled with the LOE criterion. AFR constitutive models have been used in these earlier contributions; however, in the present work, NAFR constitutive model is used, which eventually brings more destabilizing effect, as reflected in the resulting elasto-plastic tangent modulus. Furthermore, the GTN damage model with stresscontrolled void nucleation is considered in the present constitutive equations, which brings some sort of non-normality into the plastic flow (see, Needleman and Rice [83], Chu and Needleman [21]). Moreover, the present contribution focuses on the theoretical and numerical classification of the bifurcation criteria, in terms of their order of prediction of critical necking strains. The resulting constitutive equations and plastic instability criteria are implemented into the finite element code ABAQUS/standard via user-defined mechanical material behavior (UMAT) and user-defined output variables (UVARM) subroutines, respectively. Three-dimensional formulation is used for the constitutive equations; however, plane-stress conditions are considered while applying the plastic instability criteria, which is consistent with the context of thin sheet metal forming.

The present contribution is organized as follows. The constitutive equations based on the GTN elastic-plastic-damage model are presented in section 2, along with their time integration scheme and numerical validations. Section 3 is devoted to the presentation of the bifurcationbased plastic instability criteria for the prediction of diffuse and localized necking. In section 4 , numerical results in terms of forming limit diagrams, effects of associative and non-associative plasticity rules, and hierarchical classification of the instability criteria are discussed. Finally, in section 5, some concluding remarks are presented.

\section{Constitutive equations for GTN elastic-plastic-damage model}

Within the framework of large strains, a rate form for the constitutive equations is adopted to describe the material response. In order to maintain the frame-invariance, objective rates of tensor valued variables must be used. Therefore, in the following formulation of constitutive equations, the Jaumann objective rate of the Cauchy stress tensor is used, which is also fully consistent with the formulation used in the finite element (FE) code ABAQUS/Standard.

\subsection{GTN yield surface and internal variables}

Based on the limit analysis of a spherical void inside a spherical representative volume element (RVE), Gurson [17] first developed a phenomenological model for ductile damage. Tvergaard [18] and Tvergaard and Needleman [22] extended the original Gurson model by introducing void nucleation and void coalescence mechanisms in addition to void growth. The complete model is commonly referred to as Gurson-Tvergaard-Needleman (GTN) damage 
model. This model has been widely used in many applications to predict ductile fracture. The GTN yield surface is expressed as follows:

$\Phi_{\mathrm{Y}}=\left(\frac{\Sigma_{\text {eq }}}{\bar{\sigma}}\right)^{2}+2 \mathrm{q}_{1} f^{*} \cosh \left(\frac{3 \mathrm{q}_{2} \Sigma_{\mathrm{m}}}{2 \bar{\sigma}}\right)-1-\mathrm{q}_{3} f^{*^{2}} \leq 0$

where $\bar{\sigma}$ is the tensile yield stress of the fully dense matrix material, $\Sigma_{\mathrm{m}}=\frac{1}{3} \boldsymbol{\Sigma}: \mathbf{I}$ is the mean stress, $\boldsymbol{\Sigma}$ is the Cauchy stress tensor and $\mathbf{I}$ is the second-order identity tensor. $\mathrm{q}_{1}, \mathrm{q}_{2}$ and $\mathrm{q}_{3}$ are material parameters that are incorporated to account for void interaction effects. The effective porosity $f^{*} f$ was introduced by Tvergaard [19] to model the void coalescence regime. In order to account for anisotropic matrix material in the GTN damage model, the Hill'48 equivalent stress $\Sigma_{\mathrm{eq}}$ is introduced in Eq. (1), whose expression is given as follows:

$\Sigma_{\text {eq }}=\sqrt{F_{\mathrm{Y}} \Sigma_{22}-\Sigma_{33}{ }^{2}+G_{\mathrm{Y}} \Sigma_{33}-\Sigma_{11}^{2}+H_{\mathrm{Y}} \Sigma_{11}-\Sigma_{22}{ }^{2}+2 L_{\mathrm{Y}} \Sigma_{23}^{2}+2 M_{\mathrm{Y}} \Sigma_{31}^{2}+2 N_{\mathrm{Y}} \Sigma_{12}^{2}}$

where $F_{\mathrm{Y}}, G_{\mathrm{Y}}, H_{\mathrm{Y}}, L_{\mathrm{Y}}, M_{\mathrm{Y}}$ and $N_{\mathrm{Y}}$ are material anisotropy parameters, which are experimentally identified using initial yield stresses along various orientations with respect to the rolling direction. In this work, the isotropic hardening of the dense matrix material is represented by the following eommonly used isotropic hardening laws:

$\bar{\sigma}\left(\bar{\varepsilon}^{\mathrm{p}}\right)=\bar{\sigma}_{0}+K \bar{\varepsilon}^{\mathrm{p}^{n}} \quad$ (Ludwig's hardening law)

$\bar{\sigma}\left(\bar{\varepsilon}^{\mathrm{p}}\right)=K \bar{\varepsilon}^{\mathrm{p}}+\varepsilon_{0}{ }^{n} \quad$ (Swift's hardening law)

$\bar{\sigma}\left(\bar{\varepsilon}^{\mathrm{p}}\right)=\bar{\sigma}_{0}+R_{\text {sat }} 1-\exp \left(-\mathrm{C}_{\mathrm{R}} \bar{\varepsilon}^{\mathrm{p}}\right) \quad$ (Voce's hardening law)

where $\bar{\sigma}_{0}$ is the initial yield stress, $\bar{\varepsilon}^{\mathrm{p}}$ is the equivalent plastic strain, $K, \varepsilon_{0}, n, R_{\text {sat }}$ and $\mathrm{C}_{\mathrm{R}}$ are material hardening parameters for the above isotropic hardening laws. The rate form for the flow stress can be evaluated as:

$\dot{\bar{\sigma}}\left(\bar{\varepsilon}^{\mathrm{p}}\right)=\frac{\partial \bar{\sigma}}{\partial \bar{\varepsilon}^{\mathrm{p}}} \dot{\bar{\varepsilon}}^{\mathrm{p}}=h\left(\bar{\varepsilon}^{\mathrm{p}}\right) \dot{\bar{\varepsilon}}^{\mathrm{p}}$

where $h\left(\bar{\varepsilon}^{\mathrm{p}}\right)=\frac{\partial \bar{\sigma}}{\partial \bar{\varepsilon}^{\mathrm{p}}}$ is the plastic hardening slope of the dense matrix material. From the equivalence relationship of the plastic work rate, the macroscopic plastic strain rate tensor $\mathbf{D}^{\mathrm{p}}$ is related to the equivalent plastic strain rate $\dot{\bar{\varepsilon}}^{\mathrm{p}}$ as follows: 
The macroscopic plastic strain rate tensor $\mathbf{D}^{\mathrm{p}}$ is obtained using the following flow rule:

$\mathbf{D}^{\mathrm{p}}=\dot{\lambda} \frac{\partial \Phi_{\mathrm{P}}}{\partial \mathbf{\Sigma}}=\dot{\lambda} \mathbf{V}_{\mathrm{p}}$

where $\dot{\lambda}$ is the plastic multiplier, and $\Phi_{\mathrm{P}}$ is the plastic potential. $\mathbf{V}_{\mathrm{p}}$ represents the direction of the plastic flow. Note that in the case of undamaged material and associative flow rule (AFR), the plastic potential $\Phi_{\mathrm{P}}$ and the yield surface $\Phi_{\mathrm{Y}}$ coincide, while they do not coincide in the case of undamaged material and non-associative flow rule (NAFR). In the present contribution, the mathematical form of the plastic potential $\Phi_{\mathrm{P}}$ is similar to that of the undamaged part of the yield surface $\Phi_{\mathrm{Y}}$ (i.e. $\left.\Phi_{\mathrm{P}}=\left(\frac{\Sigma_{\mathrm{peq}}}{\bar{\sigma}}\right)^{2}-1 \leq 0\right)$, for which the Hill'48 anisotropy coefficients $F_{\mathrm{p}}, G_{\mathrm{p}}, H_{\mathrm{p}}, L_{\mathrm{p}}, M_{\mathrm{p}}$ and $N_{\mathrm{p}}$ are experimentally identified using strain $r$-values (i.e., Lankford coefficients).

The evolution of void volume fraction (i.e., $\dot{f}$ ) is attributed to the void growth and void nucleation. Therefore, $\dot{f}$ can be expressed as the sum of porosity evolution due to growth $\dot{f}_{\mathrm{g}}$ and nucleation $\dot{f}_{\mathrm{n}}$ :

$$
\dot{f}=\dot{f}_{\mathrm{g}}+\dot{f}_{\mathrm{n}}
$$

From the principle of dense matrix incompressibility, Tvergaard [84] derived the expression for the porosity evolution due to void growth, which mainly depends on the stress triaxiality ratio and is given as:

$\dot{f}_{\mathrm{g}}=(1-f) \mathbf{D}^{\mathrm{p}}: \mathbf{I}$

Chu and Needleman [21] modeled the void nucleation through the following "normal distribution curve" relationship:

$\dot{f}_{\mathrm{n}}=\left(\frac{A_{N}}{h}+B_{N}\right) \dot{\bar{\sigma}}+B_{N} \dot{\Sigma}_{\mathrm{m}}$

where 


$$
A_{N}=\frac{f_{N}}{s_{N} \sqrt{2 \pi}} \exp \left(-\frac{1}{2}\left(\frac{\bar{\varepsilon}^{\mathrm{p}}-\varepsilon_{N}}{s_{N}}\right)^{2}\right)
$$

and

$$
B_{N}=\frac{f_{N}}{s_{N} \bar{\sigma}_{0} \sqrt{2 \pi}} \exp \left(-\frac{1}{2}\left(\frac{\bar{\sigma}+\Sigma_{\mathrm{m}}-\sigma_{N}}{\bar{\sigma}_{0} s_{N}}\right)^{2}\right)
$$

Note that $A_{N}$ and $B_{N}$ represent the amplitudes of strain- and stress-controlled nucleation, respectively. When $A_{N}>0$ and $B_{N}=0$, void nucleation is strain-controlled, while it is stresscontrolled for $A_{N}=0$ and $B_{N}>0 . f_{N}$ represents the void volume fraction of the cavities that are likely to nucleate, $\sigma_{N}$ and $\varepsilon_{N}$ are respectively the mean stress and mean strain for nucleation, and $s_{N}$ is the standard deviation for the normal distribution curve. From Eqs. (10 11), it can be observed that maximum amplitude for stress and strain controlled nucleation takes place when $\bar{\sigma}+\Sigma_{\mathrm{m}}=\sigma_{N}$ and $\overline{\bar{c}} \mathrm{p}=\varepsilon_{N}$, respectively.

Tvergaard [18] and Tvergaard and Needleman [22] phenomenologically modeled the void coalescence phenomenon in order to simulate the rapid softening of the material near final fracture. Accordingly, the effective porosity $f^{*}$ is introduced, which remains equal to the actuat porosity $f$ as long as $f$ is less than or equal to the critical porosity $f_{c r}$. For $f>f_{c r}$ (i.e., onset of coalescence), accelerated increase in effective poresity $f^{*}$ takes place and the material rapidly lose its load carrying capacity. The effective porosity is calculated using the following phenomenological relationship:

$$
f^{*}=f_{c r}+\delta_{G T N}\left(f-f_{c r}\right)
$$

where $\delta_{G T N}$ is the accelerating factor, which is equal to 1 before the start of coalescence (i.e., $f \leq f_{\mathrm{cr}}$ ) and $\delta_{\mathrm{GTN}}>1$ in the post-coalescence regime (i.e., $f>f_{\mathrm{cr}}$ ).

\subsection{Plastic multiplier and elastic-plastic tangent modulus}

To derive the expressions of the plastic multiplier $\dot{\lambda}$ and the analytical elastic-plastic tangent modulus $\mathbf{C}^{\mathrm{ep}}$, the yield function $\Phi_{\mathrm{Y}}$ and the plastic multiplier $\dot{\lambda}$ are written in a wellknown form of Kuhn-Tucker relationship as follows:

$$
\Phi_{\mathrm{Y}} \leq 0, \quad \dot{\lambda} \geq 0, \quad \Phi_{\mathrm{Y}} \dot{\lambda}=0
$$


The above relation implies that, when $\Phi_{\mathrm{Y}}<0$, no plastic flow occurs (i.e., $\dot{\lambda}=0$ ), while a strict plastic loading (i.e., $\dot{\lambda}>0$ ) necessarily implies that $\dot{\Phi}_{\mathrm{Y}}=0$. The latter condition is known as the consistency condition and can be expanded as follows:

$$
\dot{\Phi}_{\mathrm{Y}}=\left(\frac{\partial \Phi_{\mathrm{Y}}}{\partial \boldsymbol{\Sigma}}+\frac{\partial \Phi_{\mathrm{Y}}}{\partial f^{*}} \frac{\partial f^{*}}{\partial f} \frac{B_{N}}{3} \mathbf{I}\right): \dot{\boldsymbol{\Sigma}}+\left(\frac{\partial \Phi_{\mathrm{Y}}}{\partial \bar{\sigma}}+\frac{\partial \Phi_{\mathrm{Y}}}{\partial f^{*}} \frac{\partial f^{*}}{\partial f}\left(\frac{A_{N}}{h}+B_{N}\right)\right) \dot{\bar{\sigma}}+\left(\frac{\partial \Phi_{\mathrm{Y}}}{\partial f^{*}} \frac{\partial f^{*}}{\partial f}\right) \dot{f}=0
$$

The different partial derivatives involved in the above equation can be evaluated as follows:

$$
\begin{aligned}
& \frac{\partial \Phi_{\mathrm{Y}}}{\partial \boldsymbol{\Sigma}}=\frac{2 \Sigma_{\mathrm{eq}}}{\bar{\sigma}^{2}} \frac{\partial \Sigma_{\mathrm{eq}}}{\partial \boldsymbol{\Sigma}}+\frac{\mathrm{q}_{1} \mathrm{q}_{2} f^{*}}{\bar{\sigma}} \sinh \left(\frac{3 \mathrm{q}_{2} \Sigma_{\mathrm{m}}}{2 \bar{\sigma}}\right) \mathbf{I} \\
& \frac{\partial \Phi_{\mathrm{Y}}}{\partial f^{*}}=2 \mathrm{q}_{1} \cosh \left(\frac{3 \mathrm{q}_{2} \Sigma_{\mathrm{m}}}{2 \bar{\sigma}}\right)-2 \mathrm{q}_{3} f^{*} \\
& \frac{\partial \Phi_{\mathrm{Y}}}{\partial \bar{\sigma}}=-\frac{2 \Sigma_{\mathrm{eq}}^{2}}{\bar{\sigma}^{3}}-\frac{3 \mathrm{q}_{1} \mathrm{q}_{2} f^{*} \Sigma_{\mathrm{m}}}{\bar{\sigma}^{2}} \sinh \left(\frac{3 \mathrm{q}_{2} \Sigma_{\mathrm{m}}}{2 \bar{\sigma}}\right) \\
& \frac{\partial f^{*}}{\partial f}=\delta_{G T N}
\end{aligned}
$$

Within the co-rotational material frame, the Cauchy stress rate tensor is expressed using the following hypoelastic law:

$$
\dot{\boldsymbol{\Sigma}}=\mathbf{C}^{\mathrm{e}}: \mathbf{D}-\mathbf{D}^{\mathrm{p}}=\mathbf{C}^{\mathrm{e}}: \mathbf{D}-\dot{\lambda} \mathbf{V}_{\mathrm{p}}=\mathbf{C}^{\mathrm{ep}}: \mathbf{D}
$$

where $\mathbf{D}$ represents the macroscopic strain rate tensor and $\mathbf{C}^{\mathrm{e}}$ is the fourth-order tensor of the elasticity constants. The expression for the plastic multiplier $\dot{\lambda}$ is derived by substituting Eqs. (412) and Eq. (16) into Eq. (14). The final form of $\dot{\lambda}$ is written as follows:

$$
\dot{\lambda}=\frac{\mathbf{M}: \mathbf{C}^{\mathrm{e}}: \mathbf{D}}{\mathrm{H}_{\lambda}}
$$

where

$$
\mathbf{M}=\frac{\partial \Phi_{\mathrm{Y}}}{\partial \mathbf{\Sigma}}+\frac{B_{N}}{3} \frac{\partial \Phi_{\mathrm{Y}}}{\partial f^{*}} \frac{\partial f^{*}}{\partial f} \mathbf{I}
$$

and 


$$
\mathrm{H}_{\lambda}=\mathbf{M}: \mathbf{C}^{\mathrm{e}}: \mathbf{V}_{\mathrm{p}}-\frac{h \boldsymbol{\Sigma}: \mathbf{V}_{\mathrm{p}}}{(1-f) \bar{\sigma}}\left[\frac{\partial \Phi_{\mathrm{Y}}}{\partial \bar{\sigma}}+\delta_{G T N}\left(\frac{A_{N}}{h}+B_{N}\right) \frac{\partial \Phi_{\mathrm{Y}}}{\partial f^{*}}\right]-\delta_{G T N}(1-f) \frac{\partial \Phi_{\mathrm{Y}}}{\partial f^{*}} \mathbf{V}_{\mathrm{p}}: \mathbf{I}
$$

Finally, by substituting Eq. (17) into Eq. (16), the analytical elastic-plastic tangent modulus can be derived as follows:

$$
\mathbf{C}^{\mathrm{ep}}=\mathbf{C}^{\mathrm{e}}-\beta \frac{\mathbf{C}^{\mathrm{e}}: \mathbf{V}_{\mathrm{p}} \otimes \mathbf{M}: \mathbf{C}^{\mathrm{e}}}{\mathrm{H}_{\lambda}}=\mathbf{C}^{\mathrm{e}}-\beta \frac{\mathbf{P} \otimes \mathbf{Q}}{\mathrm{H}_{\lambda}}
$$

where $\beta=1$ for plastic loading and 0 otherwise.

\subsection{Numerical implementation and time integration scheme}

The constitutive equations for the GTN damage model are implemented into the FE code ABAQUS/Standard using a user-defined material (UMAT) subroutine. Large strains and fully three-dimensional approach are considered in the formulation and its numerical implementation. The Jaumann objective rate of the Cauchy stress tensor is used in order to maintain material objectivity. Moreover, a single finite element with one integration point (specifically, C3D8R solid element in ABAQUS) is considered in the simulations, in order to ensure the conditions of a homogeneous deformation state within the solid, until the occurrence of necking. This single finite element is subjected to various linear strain paths that are those typically applied to sheet metals under in plane biaxial stretching. It can be observed that the evolution of the stress state and internal variables can be represented by a general differential equation in the generic form:

$$
\dot{\boldsymbol{x}}=g_{x}(\boldsymbol{x})
$$

where vector $\boldsymbol{x}$ encompasses all GTN model variables to be updated at the end of each loading increment. In this work, an explicit time integration scheme, specifically, the fourth-order Runge-Kutta method is adopted. With this explicit time integration scheme, a reasonable compromise can be achieved in terms of accuracy, computational cost, and convergence (see, e.g., Mansouri et al., [80]).

\subsection{Numerical validations of implemented constitutive equations}

In this subsection, the numerical validations of the implemented constitutive equations and the time integration scheme are outlined. The numerical validation is carried out in two steps. First, the numerical results corresponding to a uniaxial tension test for the original isotropic GTN damage model, predicted with the present UMAT, are compared with those obtained from the built-in isotropic GTN damage model available in ABAQUS/Standard. Then, the numerical implementation of the undamaged anisotropic plastic behavior is validated through comparisons 
with reference results available in the literature, since the present anisotropic GTN damage model is not available in ABAQUS/Standard.

\subsubsection{Validations of GTN damage model}

For the numerical validations of the present model, simulations of a uniaxial tension test with the original isotropic GTN model are carried out. Note that the original isotropic GTN model is recovered from the anisotropic one when the Lankford coefficients are set to 1 and when $F_{\mathrm{Y}}=G_{\mathrm{Y}}=H_{\mathrm{Y}}=0.5$ and $L_{\mathrm{Y}}=M_{\mathrm{Y}}=N_{\mathrm{Y}}=1.5$. Only void growth and strain-controlled nucleation (without coalescence) are considered in the simulations. The material parameters used in the simulations are summarized in Tables 1 and 2. Stress-strain curves as well as porosity evolution are shown in Fig. 1, for both the developed UMAT subroutine and the built-in ABAQUS model. As observed, the results predicted with the UMAT are in excellent agreement with those of ABAQUS built-in model, which allows validating the numerical implementation of the original isotropic GTN model.

\section{Table 1}

Elastic-plastic material parameters used in the simulations.

\begin{tabular}{ccccc}
\hline$E(\mathrm{GPa})$ & $\nu$ & $K(\mathrm{MPa})$ & $n$ & $\varepsilon_{0}$ \\
\hline 70 & 0.33 & 371.2 & 0.17 & 0.00324 \\
\hline
\end{tabular}

Table 2

GTN damage parameters for strain-controlled nucleation.

\begin{tabular}{ccccccc}
\hline$f_{0}$ & $f_{N}$ & $\varepsilon_{N}$ & $s_{N}$ & $\mathrm{q}_{1}$ & $\mathrm{q}_{2}$ & $\mathrm{q}_{3}$ \\
\hline 0.01 & 0.25 & 0.27 & 0.1 & 1.5 & 1 & 2.15 \\
\hline
\end{tabular}



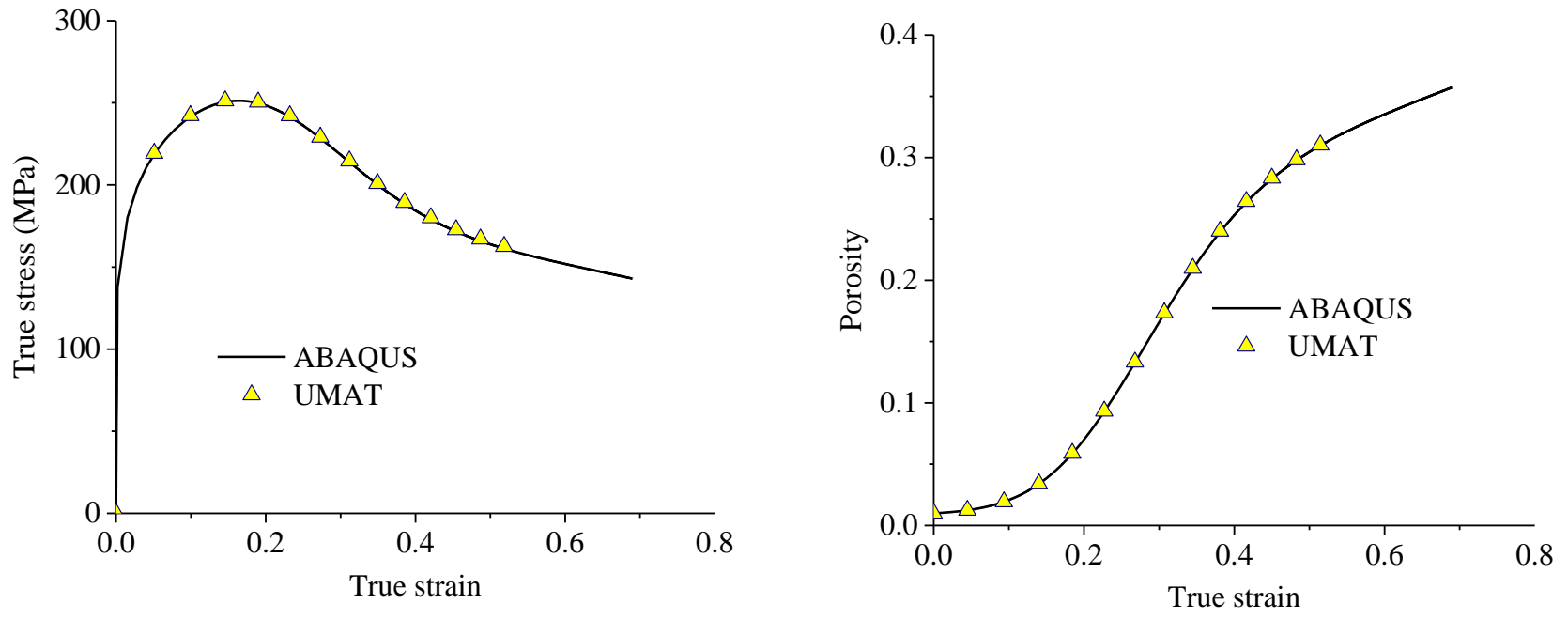

Fig. 1. Comparison between the built-in ABAQUS GTN model and the developed UMAT subroutine, with strain-controlled nucleation, in terms of true stress-strain curves (left) and porosity evolution (right), for a uniaxial tension test.

In order to achieve qualitative validations, specifically intended to strain and stresscontrolled nucleation, stress-strain curves are plotted for a uniaxial tension test with the GTN damage parameters listed in Table 3 and 4 , respectively. Note that the initial porosity is taken to be zero in order to focus attention on the void nucleation mechanism (without coalescence regime).

Table 3

GTN damage parameters for strain-controlled nucleation.

\begin{tabular}{ccccccc}
\hline$f_{0}$ & $f_{N}$ & $\varepsilon_{N}$ & $s_{N}$ & $\mathrm{q}_{1}$ & $\mathrm{q}_{2}$ & $\mathrm{q}_{3}$ \\
\hline$\theta$ & 0.25 & 0.27 & 0.1 & 1.5 & 4 & 2.15 \\
\hline
\end{tabular}

Table 3

GTN damage parameters for stress-controlled nucleation.

\begin{tabular}{ccccccc}
\hline$f_{0}$ & $f_{N}$ & $\sigma_{N}(\mathrm{MPa})$ & $s_{N}$ & $\mathrm{q}_{1}$ & $\mathrm{q}_{2}$ & $\mathrm{q}_{3}$ \\
\hline 0 & 0.25 & 400 & 1 & 1.5 & 1 & 2.15 \\
\hline
\end{tabular}

For strain-controlled nucleation, $f_{N}, \varepsilon_{N}$ and $s_{N}$ are varied, one at a time, while the remaining parameters are kept constant (see Table 3 ). The resulting stress strain curves for uniaxial tension are plotted in Fig. 2, along with the stress strain curve corresponding to undamaged isotropic elastic plastic model. From this figure, it can be observed that large values of $f_{N}$ and small values of $s_{N}$ increase the nucleation amplitude (see $\Lambda_{N}$ in Eq. (10)), which consequently accelerates the softening regime (see Figs. $2 a$ and $2 c$ ). On the other hand, the 
nucleation parameter $\varepsilon_{N}$ controls the onset of void nucleation; therefore, large values of $\varepsilon_{N}$ delay the material softening (see Fig. 2b). Note that the undamaged isotropic elastic plastic material response is recovered from strain-controlled nucleation for $f_{N}=0$, or for large values of $s_{N}$ or $\varepsilon_{N}$.

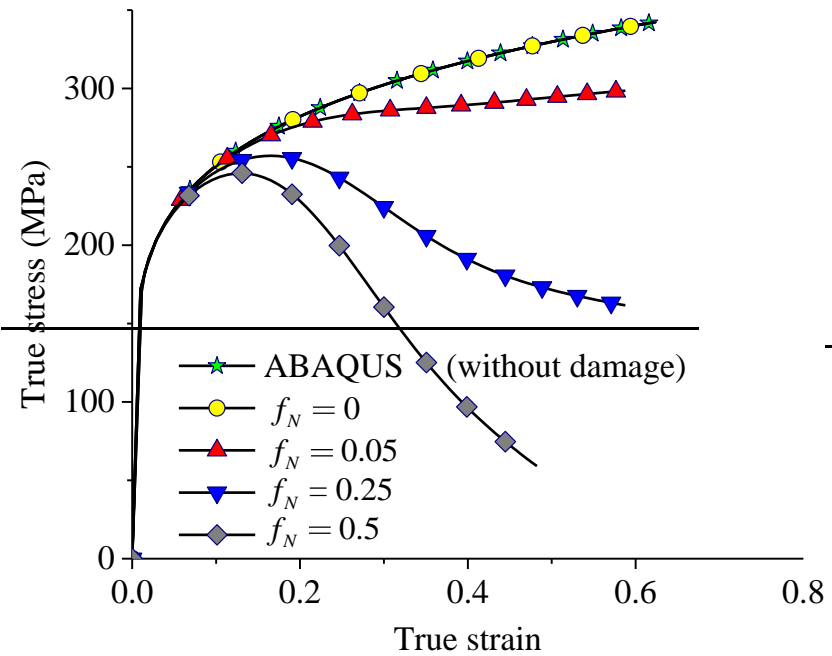

(a)

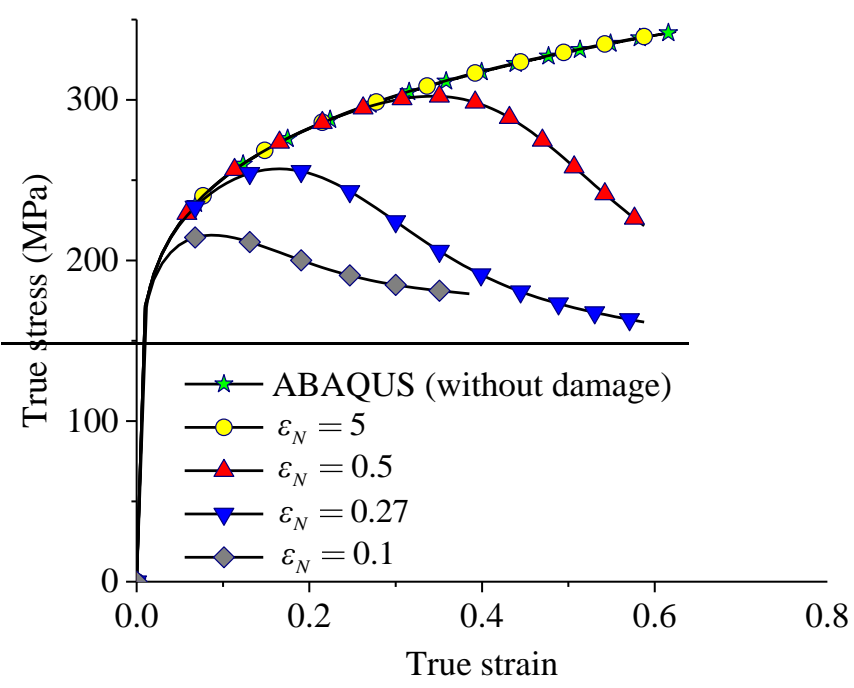

(b)

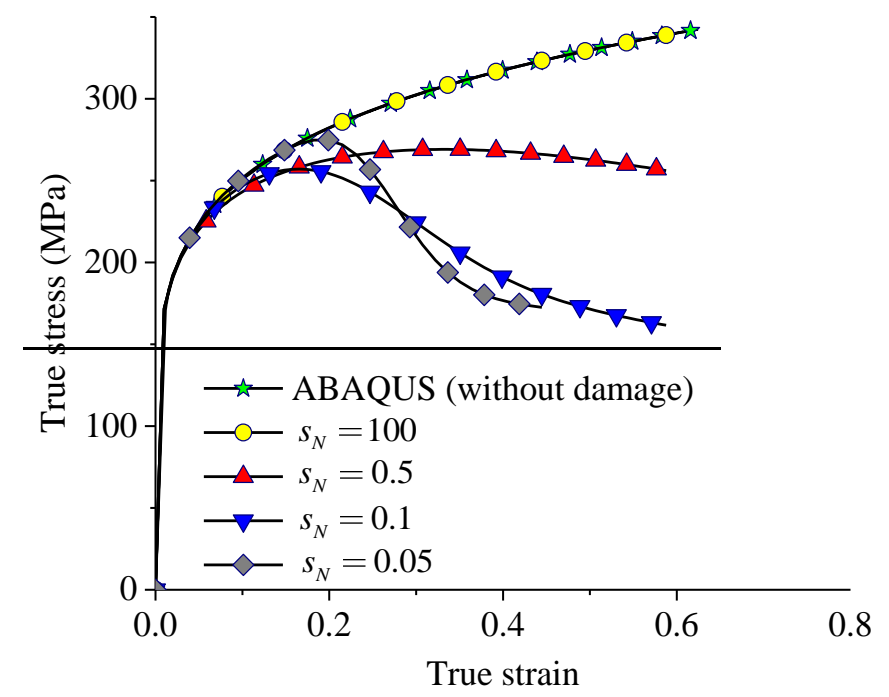

(c)

Fig. 2. Comparisons in terms of true stress-strain curves between the GTN damage model using strain-controlled nucleation (UMAT subroutine) and undamaged isotropic elastic plastic model (ABAQUS built in model) under uniaxial tension. Investigation of the effect of void nucleation parameters (a) $f_{N},\left(\right.$ b) $\varepsilon_{N}$, and (c) $s_{N}$. 
For stress-controlled nucleation, $f_{N}, \sigma_{N}$ and $s_{N}$ are varied, one at a time, while the remaining parameters are kept constant (see Table 3). The resulting stress-strain curves for uniaxial tension are plotted in Fig. 2, along with the stress-strain curve corresponding to undamaged isotropic elastic-plastic model. From this figure, it can be observed that large values of $f_{N}$ and small values of $s_{N}$ increase the nucleation amplitude (see $B_{N}$ in Eq. (11)), which consequently accelerates the softening regime (see Figs. 2a and 2c). On the other hand, the nucleation parameter $\sigma_{N}$ controls the onset of void nucleation; therefore, large values of $\sigma_{N}$ delay the material softening (see Fig. 2b). Note that the undamaged isotropic elastic-plastic material response is recovered from stress-controlled nucleation for $f_{N}=0$, or for large values of $s_{N}$ or $\sigma_{N}$.

For stress-controlled nucleation, the reference set of nucleation parameters is reported in Fable 4. In this sensitivity analysis, $f_{N}, \sigma_{N}$ and $s_{N}$ are varied, one at a time, while the remaining parameters in Table 4 are kept constant. The resulting stress-strain curves for uniaxial tension are presented in Figs. $3 a, 3 b$ and $3 c$, respectively, along with the stress strain curve corresponding to undamaged isotropic elastic plastic model. Similar trends are observed when varying the stress-controlled nucleation parameters, as for the case of strain-controlled nucleation parameters, with an undamaged isotropic elastic plastic material response recovered from stresscentrolled nucleation for $f_{N}=0$ or for large values of $s_{N}$ or $\sigma_{N}$. 


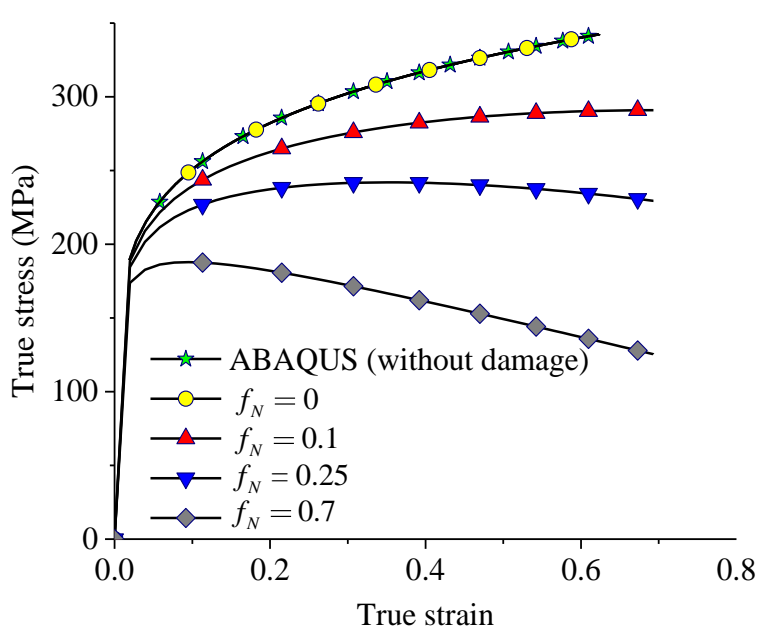

(a)

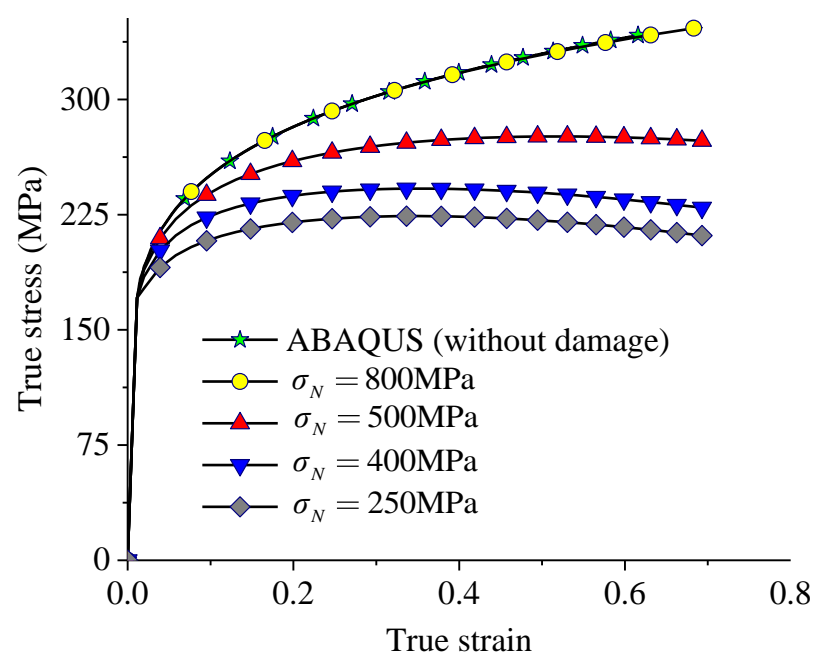

(b)

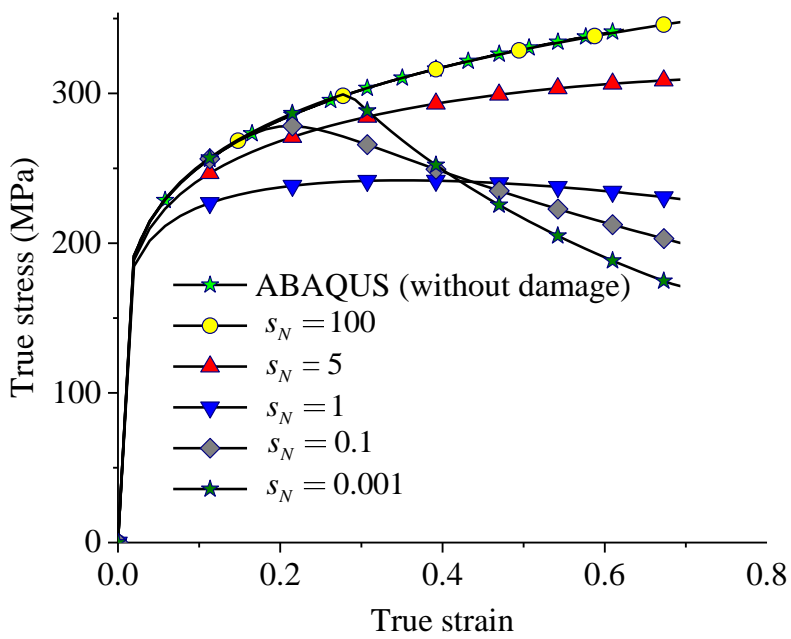

(c)

Fig. 2. Comparisons in terms of true stress-strain curves between the GTN-damage model using stress-controlled nucleation (UMAT subroutine) and undamaged isotropic elastic-plastic model (ABAQUS built-in model) under uniaxial tension. Investigation of the effect of void nucleation parameters (a) $f_{N}$, (b) $\sigma_{N}$, and (c) $s_{N}$.

\subsubsection{Validation of Hill'48 anisotropic behavior}

In order to account for the plastic anisotropy of the material, the original isotropic GTN yield surface is modified by introducing the Hill'48 equivalent stress instead of the von Mises one (see Eq. (1)). In order to validate the numerical implementation of the undamaged anisotropic material behavior, the results predicted for uniaxial flow properties, i.e., normalized flow stresses and $r$-values as functions of the tensile angle orientation with respect to the rolling direction, are shown in Fig. 3, along with the reference results reported by Neto et al. [85]. These 
types of numerical results are usually used to identify the anisotropy coefficients of the materiat. The Hill' 48 anisotropy coefficients used in the simulations are listed in Table 4. It can be seen from Fig. 3 that the predicted results are in excellent agreement with the reference ones, which validates the present implementation for the whole anisotropic behavior (i.e., $r$-values and flow stresses).

\section{Table 4}

Hill'48 anisotropy coefficients used in the simulations (Neto et al. [85]).

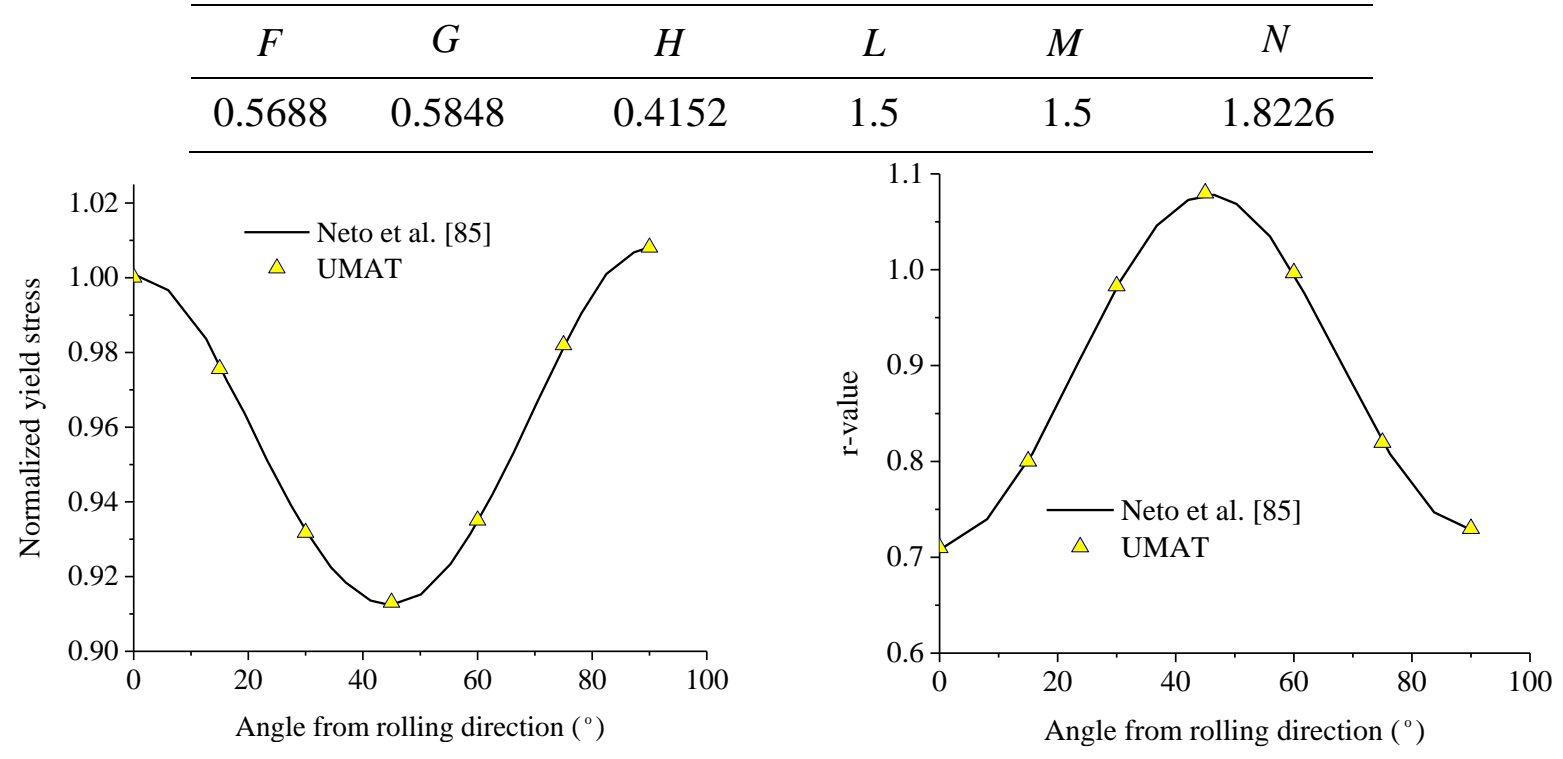

Fig. 3. Validation of the anisotropic behavior: normalized flow stresses (left), and $r$-values (right) under uniaxial tension.

In addition to the above results, validations in terms of yield locus and stress-strain curves for uniaxial tension tests at $0^{\circ}$ and $90^{\circ}$ from the rolling direction are also presented Fig. 4, which are compared with those obtained with the built-in Hill'48 model available in ABAQUS. The material parameters used in the simulations are listed in Table 5. Again, the numerical results provided by the UMAT subroutine and the built-in ABAQUS model coincide.

Table 5

Hill'48 anisotropy coefficients and Voce's hardening parameters used in the simulations.

\begin{tabular}{ccccccccc}
\hline$F$ & $G$ & $H$ & $L$ & $M$ & $N$ & $\bar{\sigma}_{0}(\mathrm{MPa})$ & $R_{\mathrm{sat}}(\mathrm{MPa})$ & $\mathrm{C}_{\mathrm{R}}$ \\
\hline 0.7 & 0.48 & 0.52 & 1.5 & 1.5 & 1.265 & 124.2 & 167 & 9.5 \\
\hline
\end{tabular}



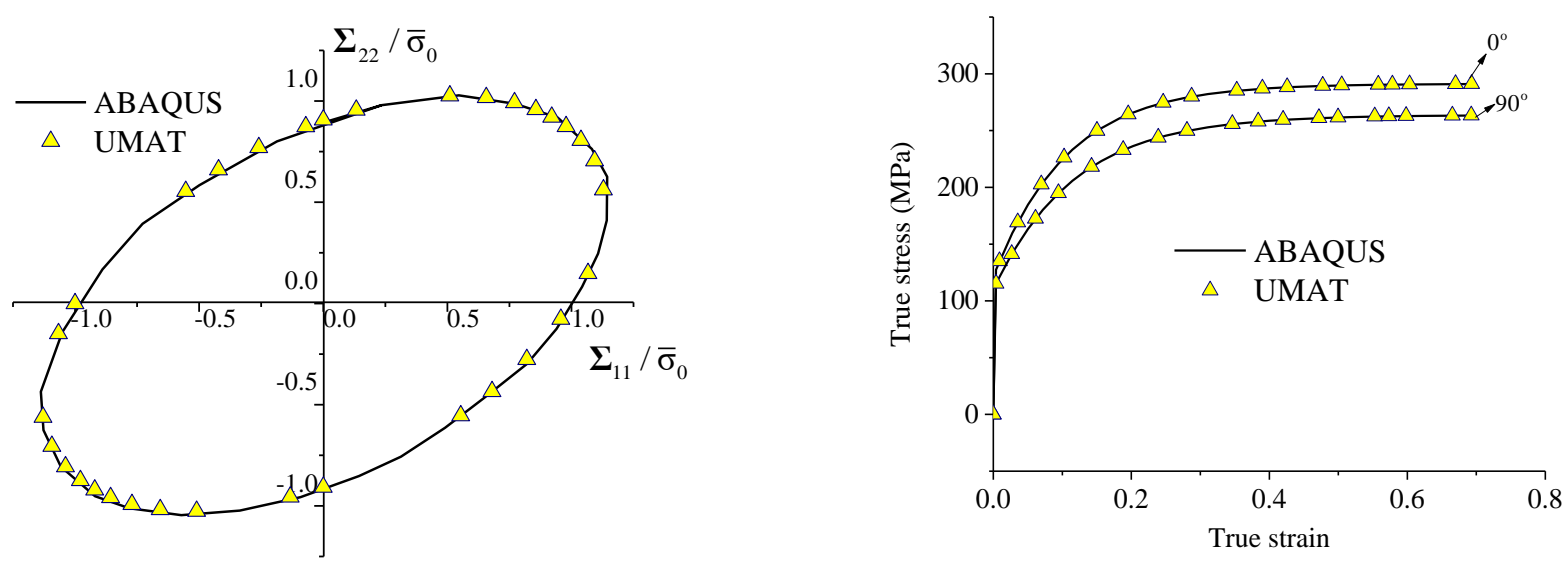

Fig. 4. Hill' 48 normalized yield surface (left), and uniaxial tensile stress-strain curves at $0^{\circ}$ and $90^{\circ}$ from the rolling direction.

\section{Bifurcation-based plastic instability criteria}

In order to predict plastic instabilities that may occur during sheet metal forming processes, various plastic instability criteria have been proposed over the last few decades. Instability eriteria which are based on the bifurcation theory are used in this paper to predict the occurrence of diffuse and localized necking. In the context of bifurcation theory, necking is viewed as an evolution of strains from a homogeneous to a heterogeneous state. Four bifurcation-based plastic instability criteria are used in this contribution, i.e., general bifurcation criterion and limit-point bifurcation criterion are used to predict diffuse necking, while loss of ellipticity criterion and loss of strong ellipticity criterion are used to predict localized necking. Prior to presenting these plastic instability criteria, the elastic-plastic tangent modulus that will be involved in the formulation of these criteria is derived hereafter.

The nominal stress tensor $\mathbf{N}$, the first Piola-Kirchhoff stress tensor $\mathbf{B}$, and the Cauchy stress tensor $\boldsymbol{\Sigma}$ are related by the following classical relationships:

$\mathbf{F} \cdot \mathbf{B}^{\mathrm{T}}=J \boldsymbol{\Sigma}=\mathbf{F} \cdot \mathbf{N}$

where $J$ is called the Jacobian, defined as the determinant of the deformation gradient $\mathbf{F}$, i.e., $J=\operatorname{det} \mathbf{F}$. Note that the nominal stress tensor and the first Piola-Kirchhoff stress tensor are the transpose of each other (i.e., $\mathbf{N}=\mathbf{B}^{\mathrm{T}}$ ). In addition, the nominal stress rate tensor $\dot{\mathbf{N}}$ and the velocity gradient $\mathbf{G}$ are related by the following constitutive relation:

$\dot{\mathbf{N}}=\mathbf{L}: \mathbf{G}$

where the fourth-order elastic-plastic tangent modulus $\mathbf{L}$ will be determined in what follows. By taking the time derivative of Eq. (22), and rearranging, the expression of the nominal stress rate tensor can be evaluated as follows: 
$\dot{\mathbf{N}}=J \mathbf{F}^{-1} \cdot \operatorname{tr} \mathbf{D} \boldsymbol{\Sigma}+\dot{\boldsymbol{\Sigma}}-\mathbf{G} \cdot \mathbf{\Sigma}$

Following an updated Lagrangian approach, i.e., $J=1$ and $\mathbf{F}=\mathbf{I}$, the expression of the nominal stress rate tensor can be simplified as:

$$
\dot{\mathbf{N}}=\dot{\boldsymbol{\Sigma}}+\operatorname{tr} \mathbf{D} \boldsymbol{\Sigma}-\mathbf{D} \cdot \boldsymbol{\Sigma}-\boldsymbol{\Sigma} \cdot \mathbf{\Omega}
$$

where $\boldsymbol{\Omega}$ is the spin tensor defined as the anti-symmetric part of the velocity gradient $\mathbf{G}$. For the sake of material objectivity, the Jaumann objective rate of the Cauchy stress tensor has been used in the present work. Therefore, the hypoelastic law for large strains, as defined in Eq. (16) using the co-rotational material frame, can be expressed in a fixed reference frame as follows:

$\dot{\boldsymbol{\Sigma}}^{\mathrm{J}}=\mathbf{C}^{\mathrm{e}}: \mathbf{D}-\mathbf{D}^{\mathrm{p}}=\mathbf{C}^{\mathrm{ep}}: \mathbf{D}$

where $\dot{\boldsymbol{\Sigma}}^{\mathrm{J}}$ represents the Jaumann objective rate of the cauchy stress tensor, which is defined by the following relationship:

$$
\dot{\Sigma}^{J}=\dot{\Sigma}-\Omega \cdot \Sigma+\Sigma \cdot \Omega
$$

Finally, by combining Eqs. (25-27), the expression of the nominal stress rate tensor can be obtained as:

$$
\dot{\mathbf{N}}=\mathbf{C}^{\mathrm{ep}}: \mathbf{D}+\operatorname{tr} \mathbf{D} \boldsymbol{\Sigma}-\mathbf{D} \cdot \boldsymbol{\Sigma}-\boldsymbol{\Sigma} \cdot \mathbf{\Omega}
$$

From the comparison of Eqs. (23) and (28), the expression of the tangent modulus $\mathbf{L}$ can be derived as:

$$
\mathbf{L}=\mathbf{C}^{\mathrm{ep}}+\mathbf{C}_{1}-\mathbf{C}_{2}-\mathbf{C}_{3}
$$

where the analytical elastic-plastic tangent modulus $\mathbf{C}^{\mathrm{ep}}$ is given by Eq. (20), while $\mathbf{C}_{1}, \mathbf{C}_{2}$ and $\mathbf{C}_{3}$ are composed of convective stress components, which are induced by the large strain framework. Their expressions depend only on Cauchy stress components, and are given by the following expressions:

$$
\begin{aligned}
& \mathrm{C}_{1 \mathrm{ijkl}}=\Sigma_{\mathrm{ij}} \delta_{\mathrm{kl}} \\
& \mathrm{C}_{2 \mathrm{ijkl}}=\frac{1}{2} \Sigma_{\mathrm{jk}} \delta_{\mathrm{il}}+\Sigma_{\mathrm{jl}} \delta_{\mathrm{ik}} \\
& \mathrm{C}_{3 \mathrm{ijkl}}=\frac{1}{2} \Sigma_{\mathrm{ik}} \delta_{\mathrm{jl}}-\Sigma_{\mathrm{il}} \delta_{\mathrm{jk}}
\end{aligned}
$$

where 
$\delta_{i j}= \begin{cases}1 & \text { for } \mathrm{i}=\mathrm{j} \\ 0 & \text { for } \mathrm{i} \neq \mathrm{j}\end{cases}$

\subsection{Formulation of bifurcation-based plastic instability criteria}

The different bifurcation-based plastic instability criteria, which will be used in the present contribution for the prediction of FLDs, are briefly discussed in what follows. In the earlier work presented by Bouktir et al. [82], the FLDs were predicted by using these instability criteria coupled with the CDM approach and associative plasticity. By contrast, in the present work, nonassociative plasticity with non-normal plastic flow rule are considered together with the anisotropic GTN damage model.

\subsubsection{General bifurcation criterion}

A general condition for homogeneous strain state for rate-independent materials has been introduced by Drucker [68] and Hill [69], which can be expressed mathematically as the positiveness of the second-order work:

$\dot{\mathbf{F}}: \mathbf{L}^{\mathrm{B}}: \dot{\mathbf{F}}>0$

where $\mathbf{L}^{B}$ is a fourth-order tensor, defined as the tangent modulus relating the first PiolaKirchhoff stress tensor $\mathbf{B}$ to the deformation gradient $\mathbf{F}$, as given by the following relationship:

$\dot{\mathbf{B}}=\mathbf{L}^{\mathrm{B}}: \dot{\mathbf{F}}$

As the nominal stress tensor $\mathbf{N}$ and the first Piola-Kirchhoff stress tensor $\mathbf{B}$ are the transpose of each other, their respective tangent moduli are related by the following relationship:

$\mathrm{L}_{\mathrm{ijkl}}^{\mathrm{B}}=\mathrm{L}_{\mathrm{jikl}}$

The above criterion, given by the positiveness of the second-order work (see Eq. (32)), appears to be conservative, since it provides a lower bound for the initiation of diffuse or localized necking. The resulting sufficient condition for homogeneous deformation state requires that the quadratic form written in Eq. (32) be positive definite and, in practice, requires the positiveness of all the eigenvalues of the symmetric part of the tangent modulus $\mathbf{L}^{\mathrm{B}}$.

\subsubsection{Limit-point bifurcation criterion}

Following the above general bifurcation (GB) criterion, it has been observed that the predicted limit strains are too low in some practical applications (see, e.g., Abed-Meraim et al. [86]). As an alternative, Valanis [70] introduced a less conservative criterion, as compared to the 
GB criterion, named as the limit-point bifurcation (LPB) criterion. According to this criterion, diffuse necking takes place when the first Piola-Kirchhoff stress attains a stationary value, i.e.,

$$
\dot{\mathbf{B}}=\mathbf{L}^{\mathrm{B}}: \dot{\mathbf{F}}=\mathbf{0}
$$

which suggests that bifurcation is associated with the singularity of the tangent modulus $\mathbf{L}^{\mathrm{B}}$, i.e., $\operatorname{det} \mathbf{L}^{\mathrm{B}}=0$, or equivalently, when one of its eigenvalues becomes equal to zero. It is noteworthy that, in the case of small strains, associative flow rules and undamaged material, the GB criterion and LPB criterion predict equivalent forming limit diagrams, due to the symmetry of the involved tangent modulus.

\subsubsection{Loss of ellipticity criterion}

Stören and Rice [72] and Rice [73] investigated the occurrence of localized necking in the form of a localization band, across which the velocity gradient is discontinuous. This localization bifurcation corresponds to the loss of ellipticity (LOE) of the partial differential equations that govern the associated boundary value problem. The localization band is described by a planar discontinuity band defined by its normal vector $\mathbf{n}$, as schematically illustrated in Fig. 5. The abrupt jump in the velocity gradient, $\llbracket \mathbf{G} \rrbracket=\mathbf{G}^{\mathrm{H}}-\mathbf{G}^{\mathrm{B}}$, across the localization band, can be expressed by using Maxwell's compatibility equation:

$$
\llbracket \mathbf{G} \rrbracket=\dot{\gamma} \otimes \mathbf{n}
$$

where $\mathbf{G}^{\mathrm{B}}$ and $\mathbf{G}^{\mathrm{H}}$ represent the velocity gradient inside and outside the localization band, respectively. The vector $\dot{\gamma}=\llbracket \mathbf{G} \rrbracket \cdot \mathbf{n}$ is the jump amplitude vector, which describes the localization mode (e.g., shear bifurcation mode when $\dot{\gamma} \perp \mathbf{n}$ ). 


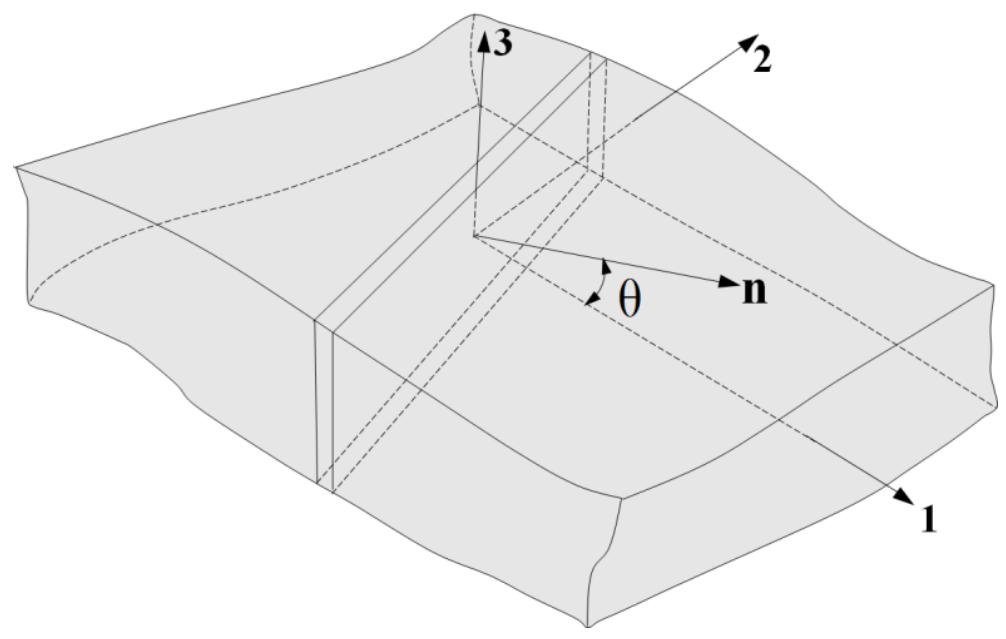

Fig. 5. Schematic illustration of a localization band within a sheet metal.

The equilibrium of forces can be expressed in terms of jump of nominal stress rate tensor across the localization band, as follows:

$\mathbf{n} \cdot \llbracket \dot{\mathbf{N}} \rrbracket=\mathbf{0}$

$\mathbf{n} \cdot \dot{\mathbf{N}}^{\mathrm{H}}-\dot{\mathbf{N}}^{\mathrm{B}}=\mathbf{0}$

where $\dot{\mathbf{N}}^{\mathrm{B}}$ and $\dot{\mathbf{N}}^{\mathrm{H}}$ represent the nominal stress rate tensor inside and outside the localization band, respectively. By combining Eqs. (23), (36) and (37), the critical condition for the occurrence of localized necking can be expressed as the singularity of the acoustic tensor $\mathbf{Q}=\mathbf{n} \cdot \mathbf{L} \cdot \mathbf{n}$ :

$\operatorname{det} \mathbf{Q}=\operatorname{det} \mathbf{n} \cdot \mathbf{L} \cdot \mathbf{n}=0$

In practice, localization bifurcation is predicted numerically during the process of loading when the minimum value of the determinant of the acoustic tensor, for all possible orientations of the normal $\mathbf{n}$ to the localization band, becomes non-positive.

\subsubsection{Loss of strong ellipticity criterion}

Similar to the loss of ellipticity criterion, Bigoni and Zaccaria [87] and Bigoni [88] proposed the loss of strong ellipticity criterion (LOSE) for the prediction of localized necking. It can be demonstrated that LOSE criterion is a special case of GB theory. Indeed, in the latter theory, no restrictive condition is imposed on the form of the velocity gradient $\dot{\mathbf{F}}$ (see Eq. (32)). However, if the compatibility condition proposed by Neilsen and Schreyer [75] is imposed on the velocity gradient, then LOSE criterion is recovered from GB criterion. LOSE criterion states that localized necking does not take place as long as the following condition holds: 
where the acoustic tensor $\mathbf{Q}=\mathbf{n} \cdot \mathbf{L} \cdot \mathbf{n}$ is the same as that defined in the previous LOE criterion. Practically, LOSE condition is equivalent to the condition of positive definiteness of the acoustic tensor $\mathbf{Q}$, which requires the positiveness of all the eigenvalues of the symmetric part of the acoustic tensor $\mathbf{Q}$.

It is interesting to note that, within the framework of small strains, associative plastic flow rule, and with no coupling to damage, the acoustic tensor is symmetric and therefore, both LOE criterion and LOSE criterion predict equivalent FLDs.

\subsection{Hierarchical classification for the bifurcation-based criteria}

In this subsection, a theoretical classification for the bifurcation-based plastic instability criteria, according to their order of prediction of necking, is established. For this purpose, let us consider a matrix $\mathbf{K}$ and its symmetric part (i.e., $\mathbf{K}^{\mathrm{sym}}=1 / 2\left(\mathbf{K}+\mathbf{K}^{\mathrm{T}}\right)$, where $\mathbf{K}^{\mathrm{T}}$ denotes the transpose of matrix $\mathbf{K}$ ). It has been shown in the literature (see, e.g., Abed-Meraim [89]) that the real parts of the eigenvalues $\mu_{i}^{\mathbf{K}}$ of matrix $\mathbf{K}$ are bounded by the minimum and the maximum eigenvalue of its symmetric part $\left(\mathbf{K}^{\text {sym }}\right)$ :

$$
\min _{S p\left(\mathbf{K}^{\mathrm{sym}}\right)} \mu_{i}^{\mathbf{K}^{\mathrm{sym}}} \leq \operatorname{Re}_{S p(\mathbf{K})} \mu_{i}^{\mathbf{K}} \leq \max _{S p\left(\mathbf{K}^{\mathrm{sym}}\right)} \mu_{i}^{\mathbf{K}^{\mathrm{sym}}}
$$

where $\underset{S p(\mathbf{K})}{\operatorname{Re}} \mu_{i}^{\mathbf{K}} \quad$ represent the real parts of the eigenvalues $\mu_{i}^{\mathbf{K}}(1 \leq i \leq n)$ of matrix $\mathbf{K}$, while $\min _{S p\left(\mathbf{K}^{\text {sym }}\right)} \mu_{i}^{\mathbf{K}^{\text {sym }}}$ and $\max _{S p\left(\mathbf{K}^{\text {sym }}\right)} \mu_{i}^{\mathbf{K}^{\text {sym }}}$ denote the smallest and the largest eigenvalue of matrix $\mathbf{K}^{\text {sym }}$. Based on Eq. (40), the following inequalities can be derived, which involve the eigenvalues of the tangent modulus $\mathbf{L}^{\mathrm{B}}$ and the acoustic tensor $\mathbf{Q}$ and of their symmetric parts $\mathbf{L}^{\mathrm{B}}{ }^{\text {sym }}$ and $\mathbf{Q}^{\text {sym }}$, respectively:

$$
\begin{aligned}
& \min _{S p\left(\mathbf{L}^{\mathrm{B}^{\mathrm{sym}}}\right)} \mu_{i}^{\mathbf{L}^{\mathrm{B}} \mathrm{sym}} \leq \underset{S p\left(\mathbf{L}^{\mathrm{B}}\right)}{\operatorname{Re}} \mu_{i}^{\mathbf{L}^{\mathrm{B}}} \\
& \min _{S p\left(\mathbf{Q}^{\mathrm{sym}}\right)} \mu_{i}^{\mathbf{Q}^{\mathrm{sym}}} \leq \operatorname{Re}_{S p(\mathbf{Q})} \mu_{i}^{\mathbf{Q}}
\end{aligned}
$$

According to Eq. (41), the singularity of the tangent modulus $\mathbf{L}^{\mathrm{B}}$ cannot occur before the loss of positive definiteness of the symmetric part of the tangent modulus $\mathbf{L}^{\mathrm{B}}$. This mathematical property implies that, for the prediction of diffuse necking, the GB criterion is more conservative than the LPB criterion. Similarly, Eq. (42) implies that the singularity of the acoustic tensor $\mathbf{Q}$ 
cannot occur before the loss of positive definiteness of the symmetric part of tensor $\mathbf{Q}$. In other words, for the prediction of localized necking, the LOSE criterion is more conservative than the LOE criterion.

From the above discussion, the following theoretical classification of the bifurcation-based criteria can be established (see also Fig. 6):

- The GB criterion provides a lower bound for the occurrence of any type of necking (diffuse or localized necking);

- The LOE criterion provides an upper bound for the occurrence of localized necking;

- The LPB criterion is less conservative than the GB criterion;

- The LOSE criterion is more conservative than the LOE criterion.

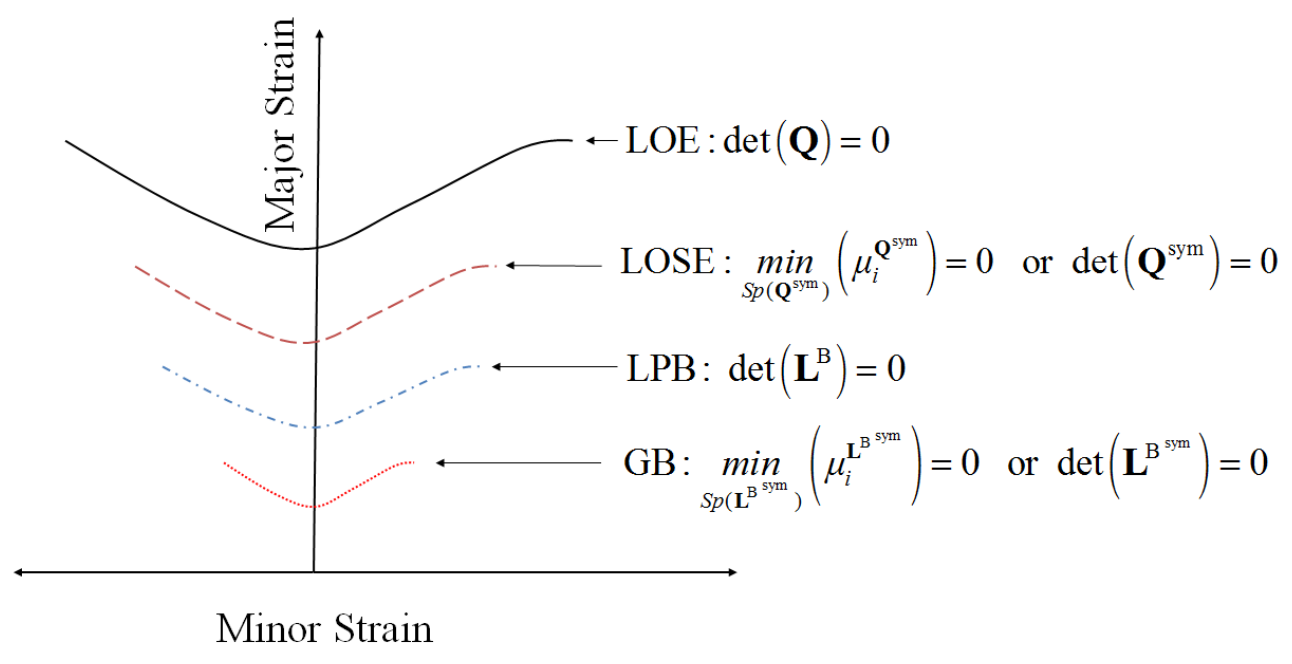

Fig. 6. Illustration of the theoretical classification of the four bifurcation-based criteria.

\subsection{Plane-stress conditions}

It should be recalled that the constitutive equations have been developed in Section 2 by following a fully three-dimensional approach. However, the plane-stress conditions are assumed during the implementation of the plastic instability criteria, since the intended application of the present numerical tool is the prediction of ductility limits in thin sheet metals.

The tangent modulus $\mathbf{L}$, which plays a key role in the formulation of the above-discussed bifurcation-based criteria, is reformulated within the framework of plane-stress conditions. Accordingly, the relationship between the nominal stress rate tensor and velocity gradient, defined by Eq. (23), can be rewritten for plane-stress conditions as follows:

$\dot{\mathrm{N}}_{\mathrm{ij}}=\mathrm{L}_{\alpha \beta \gamma \delta}^{\mathrm{PS}} \mathrm{G}_{\gamma \delta}$, with $\alpha, \beta, \gamma, \delta=1,2$ 
where $\mathbf{L}^{\mathrm{PS}}$ represents the tangent modulus for plane-stress conditions. $\mathbf{L}^{\mathrm{PS}}$ can be expressed in terms of three-dimensional tangent modulus $\mathbf{L}$ as follows:

$$
\mathrm{L}_{\alpha \beta \gamma \delta}^{\mathrm{PS}}=\mathrm{L}_{\alpha \beta \gamma \delta}-\frac{\mathrm{L}_{\alpha \beta 33} \mathrm{~L}_{33 \gamma \delta}}{\mathrm{L}_{3333}}
$$

Note that, for the prediction of localized necking under the plane-stress conditions, the localization band is sought in the plane of the sheet, defined by an in-plane band orientation angle $\theta$ (see Fig. 5).

\section{Prediction of ductility limits with GTN damage model and bifurcation- based instability criteria}

In this section, the GTN elastic-plastic-damage model, described in Section 2, is coupled with the bifurcation-based plastic instability criteria for the prediction of forming limit diagrams (FLDs). The resulting numerical tool is implemented into the FE code ABAQUS/Standard within the framework of large strains. In order to investigate plastic instabilities that are inherent to the material alone, which exclude all structural (geometric) effects, a single finite element with one integration point is used in the simulations, which results in a homogeneous strain state in the material prior to the occurrence of plastic instability. Boundary conditions corresponding to in-plane biaxial stretching are applied to the finite element, in order to generate various proportional loading paths with constant strain path ratios ranging from uniaxial tension to balanced biaxial tension. The single finite element, specifically C3D8R solid element in ABAQUS, is shown in Fig. 7 along with the associated boundary conditions. $U_{1}$ and $U_{2}$ represent the prescribed displacements along the major and minor directions, respectively. In order to maintain a constant strain-path ratio throughout the loading, the minor displacement $U_{2}$ is defined as a function of the major displacement $U_{1}$ via a user-defined displacement (DISP) subroutine. The instability criteria are implemented in ABAQUS via a user-defined output variables (UVARM) subroutine. It should be noted that the full GTN damage model presented in Section 2 is not available in the ABAQUS/Standard finite element code. Indeed, only the Gurson model, including void growth and strain-controlled nucleation mechanisms, is available in ABAQUS/Standard code. Moreover, the non-associative flow rule and stress-controlled nucleation are not available in ABAQUS/Standard, which has motivated in part our own implementation of the extended GTN model in ABAQUS/Standard via UMAT subroutine. Note that at the end of each loading increment, when the equilibrium condition is satisfied, the updated tangent modulus $\mathbf{C}^{\mathrm{ep}}$ as well as the associated internal variables are transferred from the UMAT subroutine to the UVARM subroutine, where the calculations of elastic-plastic tangent moduli (i.e., $\mathbf{L}$ and $\mathbf{L}^{\mathrm{B}}$ ) are performed and the plastic instability criteria are evaluated. 
The effects of non-associative plasticity with non-normal plastic flow on the prediction of plastic instabilities are investigated hereafter. First, the elastic-plastic undamaged model based on the Hill'48 plastic anisotropy is coupled with the four bifurcation-based instability criteria. The FLDs are predicted by considering both associative and non-associative plasticity and compared with each other. Then, the GTN damage model with strain-controlled nucleation is considered; first, in the case of associative plasticity, and then, in the case of non-associative plasticity. Finally, the case of non-associative plasticity with stress-controlled nucleation is combined with the four bifurcation-based instability criteria. For each variant of the constitutive model mentioned above, numerical classification of the four bifurcation-based instability criteria, in terms of their order of prediction of the occurrence of necking, is established and discussed. The elasticity constants and Ludwig's isotropic hardening parameters for the fictitious material used in the simulations are listed in Table 6.

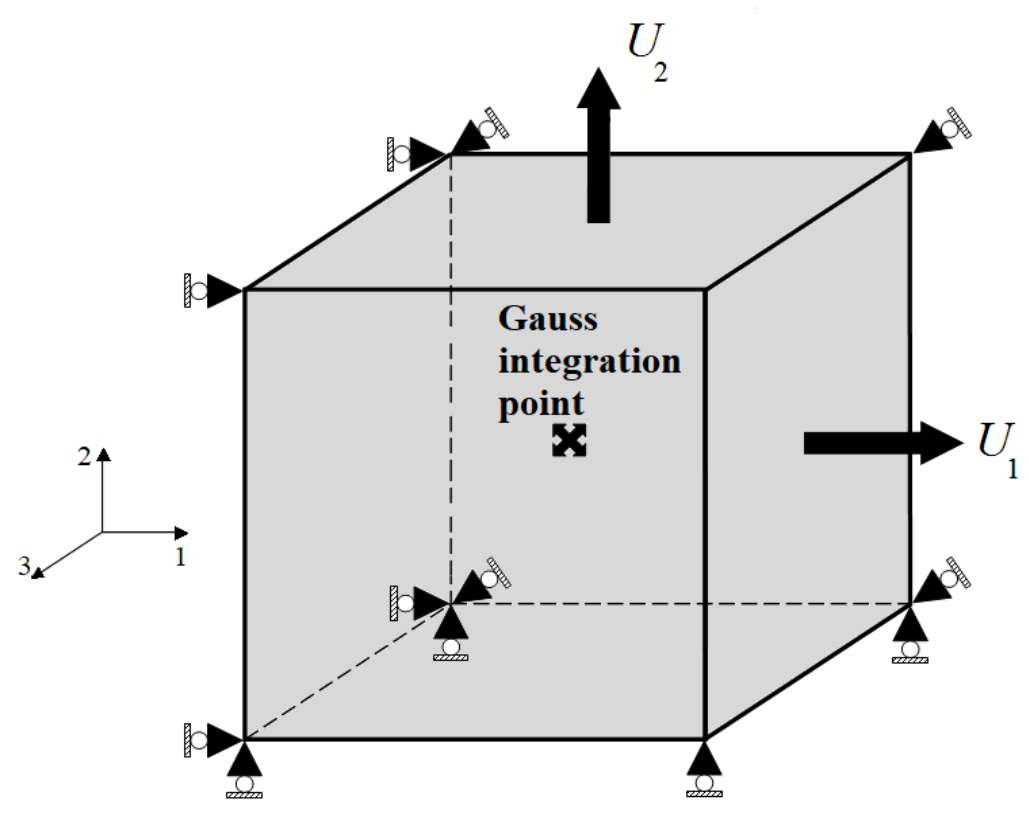

Fig. 7. Presentation of a single finite element (C3D8R) and the associated boundary conditions.

Table 6

Elasticity constants and Ludwig's hardening parameters.

\begin{tabular}{ccccc}
\hline$E(\mathrm{GPa})$ & $\nu$ & $K(\mathrm{MPa})$ & $n$ & $\bar{\sigma}_{0}(\mathrm{MPa})$ \\
\hline 210 & 0.3 & 443.59 & 0.219 & 300 \\
\hline
\end{tabular}

\subsection{Undamaged anisotropic elastic-plastic model}

In this section, an undamaged elastic-plastic model with Hill'48 plastic anisotropy is considered for the prediction of FLDs. For this purpose, the initial porosity $f_{0}$ and the Gaussian amplitude $f_{N}$, involved in the constitutive equations in Section 2, are set equal to 0. Moreover, 
the void interaction parameters (i.e., $\mathrm{q}_{1}, \mathrm{q}_{2}$ and $\mathrm{q}_{3}$ ) are set equal to 1 . The FLDs are predicted for both cases of associative and non-associative plastic flow rule. The Hill'48 anisotropy parameters for both the yield surface and the plastic potential are listed in Table 7.

\section{Table 7}

Hill'48 anisotropy coefficients for non-associative plasticity.

\begin{tabular}{cccccccccccc}
\hline$F_{\mathrm{Y}}$ & $G_{\mathrm{Y}}$ & $H_{\mathrm{Y}}$ & $L_{\mathrm{Y}}$ & $M_{\mathrm{Y}}$ & $N_{\mathrm{Y}}$ & $F_{\mathrm{P}}$ & $G_{\mathrm{P}}$ & $H_{\mathrm{P}}$ & $L_{\mathrm{P}}$ & $M_{\mathrm{P}}$ & $N_{\mathrm{P}}$ \\
\hline 0.251 & 0.297 & 0.703 & 1.5 & 1.5 & 1.29 & 0.215 & 0.347 & 0.653 & 1.5 & 1.5 & 1.32 \\
\hline
\end{tabular}

Fig. 8 shows the corresponding FLDs predicted by using the four bifurcation criteria. Note that strain localization does not occur in the right-hand side of the FLD (i.e., for positive biaxial strain-path ratios). Indeed, in the works of Mansouri et al. (2014) and Chalal and Abed-Meraim (2015), it has been shown that, using the bifurcation theory along with phenomenological models with smooth yield surface, the occurrence of strain localization for positive biaxial strain-path ratios requires the critical hardening modulus to be strongly negative, which can be achieved by the consideration of damage-induced softening. Moreover, from the comparison of Fig. 8a and Fig. 8b, it can be clearly observed that the consideration of non-associative plasticity, which results in a non-symmetric analytical elastic-plastic tangent modulus, leads to the prediction of quite distinct necking limit strains for the four bifurcation-based plastic instability criteria.

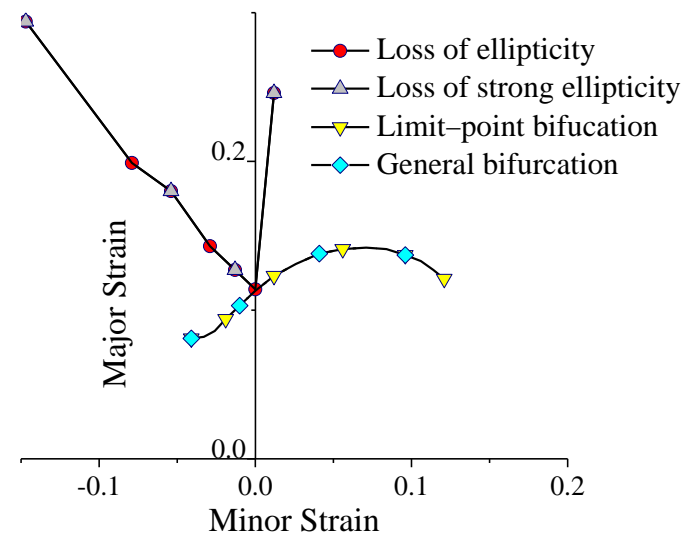

(a)

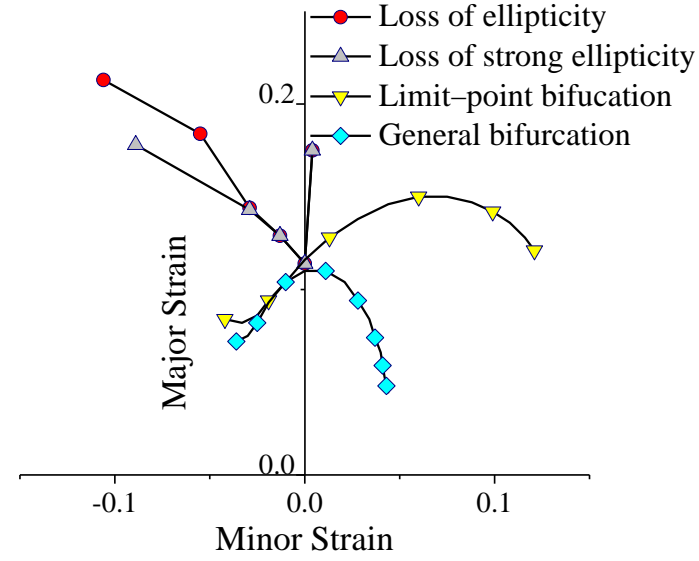

(b)

Fig. 8. FLDs predicted by the four bifurcation-based instability criteria coupled with the undamaged elastic-plastic model. Case of associative plasticity (left) and case of non-associative plasticity (right). 


\subsection{Strain-controlled nucleation and associative plasticity}

In this section, the GTN damage model with strain-controlled nucleation and associative plasticity is considered for the prediction of FLDs. Void nucleation amplitudes are $A_{N}>0$, $B_{N}=0$. In this case of associative plasticity, the plastic potential $\Phi_{\mathrm{P}}$ is taken the same as the yield surface $\Phi_{\mathrm{Y}}$, which leads to the classical normal plastic flow rule. This implies that:

$$
\mathbf{M}=\frac{\partial \Phi_{\mathrm{Y}}}{\partial \boldsymbol{\Sigma}}=\frac{\partial \Phi_{\mathrm{P}}}{\partial \boldsymbol{\Sigma}}=\mathbf{V}_{\mathrm{p}}
$$

and

$$
\mathbf{C}^{\mathrm{ep}}=\mathbf{C}^{\mathrm{e}}-\beta \frac{\mathbf{C}^{\mathrm{e}}: \mathbf{M} \otimes \mathbf{M}: \mathbf{C}^{\mathrm{e}}}{\mathrm{H}_{\lambda}}
$$

It is interesting to note that the analytical elastic-plastic tangent modulus $\mathbf{C}^{\mathrm{ep}}$ becomes symmetric in this special case. However, the localization tangent modulus $\mathbf{L}$ remains nonsymmetric, since large strain framework in considered, which involves non-zero values of convective stress components. The GTN damage parameters used in the simulations, which correspond to two fictitious materials, i.e. M1 and M2, are reported in Table 8. The Hill'48 anisotropy parameters for both materials are $F=G=H=0.5$ and $L=M=N=1.5$, which corresponds to von Mises isotropic plasticity.

\section{Table 8}

GTN damage parameters for strain-controlled nucleation.

\begin{tabular}{cccccccccc}
\hline Material & $f_{0}$ & $f_{N}$ & $\varepsilon_{N}$ & $s_{N}$ & $\mathrm{q}_{1}$ & $\mathrm{q}_{2}$ & $\mathrm{q}_{3}$ & $f_{c r}$ & $\delta_{G T N}$ \\
\hline $\mathrm{M} 1$ & 0.01 & 0.1 & 0.3 & 1.5 & 1.5 & 1 & 2.15 & 0.0601 & 20 \\
\hline $\mathrm{M} 2$ & 0.02 & 0.2 & 0.35 & 1.5 & 1.5 & 1 & 2.15 & 0.04 & 22 \\
\hline
\end{tabular}

Figure 9 shows the predicted FLDs for the studied materials M1 and M2, using the four instability criteria. It is noteworthy that only two distinct FLDs are observed, which correspond to diffuse necking (predicted by GB and LPB criteria), and localized necking (predicted by LOSE and LOE criteria). Similar results have been reported by Abed-Meraim et al. [86] and Bouktir et al. [82], using the CDM approach and associative plasticity. The reason behind this observation is that the non-symmetric part of the tangent modulus $\mathbf{L}$, which is due to the convective stress components, is not significant enough to provide separate FLDs for localized necking (as predicted by LOE and LOSE criteria), and diffuse necking (as predicted by GB and LPB criteria). Nevertheless, the theoretical classification established in the previous section is 
well respected. More specifically, the GB criterion represents a lower bound to all the bifurcation criteria, in terms of necking prediction, while the LOE criterion provides an upper bound.
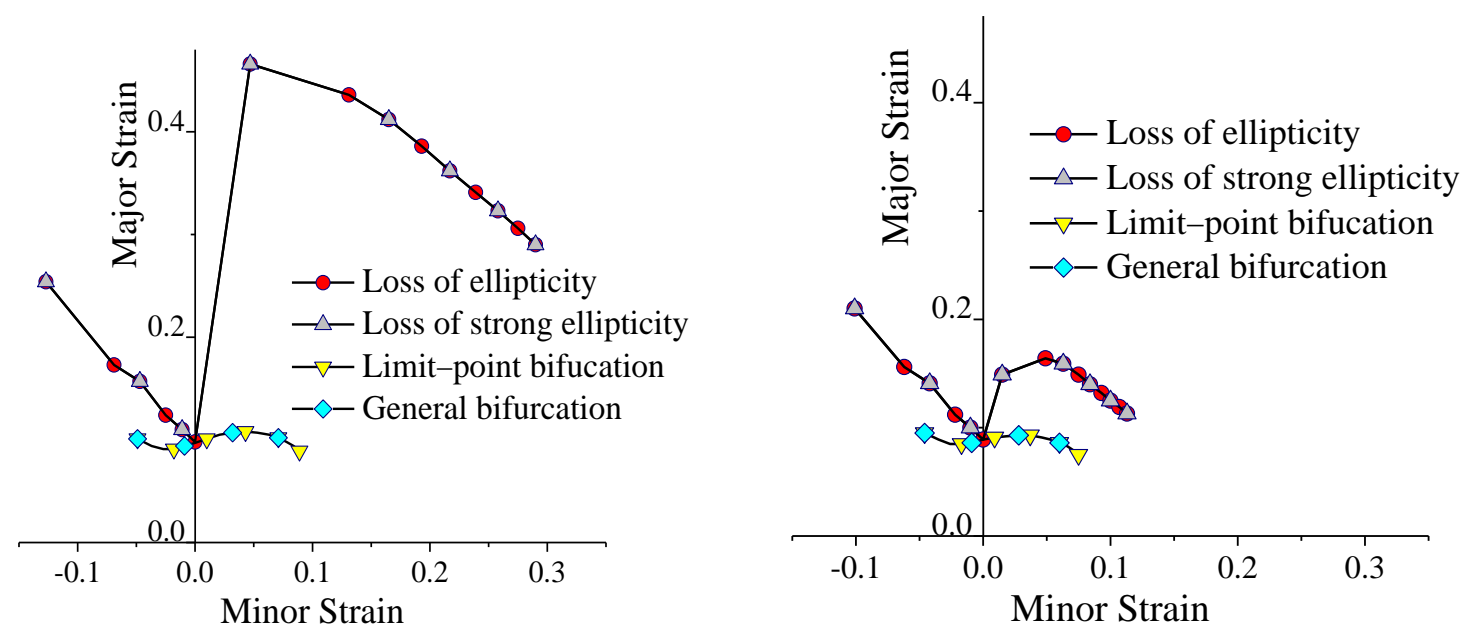

Fig. 9. FLDs predicted by the four bifurcation-based instability criteria coupled with the GTN damage model and strain-controlled nucleation. Case of associative plasticity: (left) material M1, and (right) material M2.

In order to further analyze the above predictions, the true stress-strain curves and the porosity evolution curves are plotted in Fig. 10, for three strain loading paths corresponding to uniaxial tension (UT), plane-strain tension (PST), and balanced biaxial tension (BBT). Note that, for conciseness, only results corresponding to material M1 are shown. It can be seen, from the comparison of the strain levels involved in Figs. 9 and 10, that diffuse necking, predicted by the GB and LPB criteria, takes place in the positive hardening regime, well before the onset of the coalescence stage for the three strain loading paths. With regard to localized necking, the latter also occurs in the positive hardening regime for the UT and PST loading paths, while negative hardening modulus is required for the BBT loading path. These observations are consistent with the available literature. 

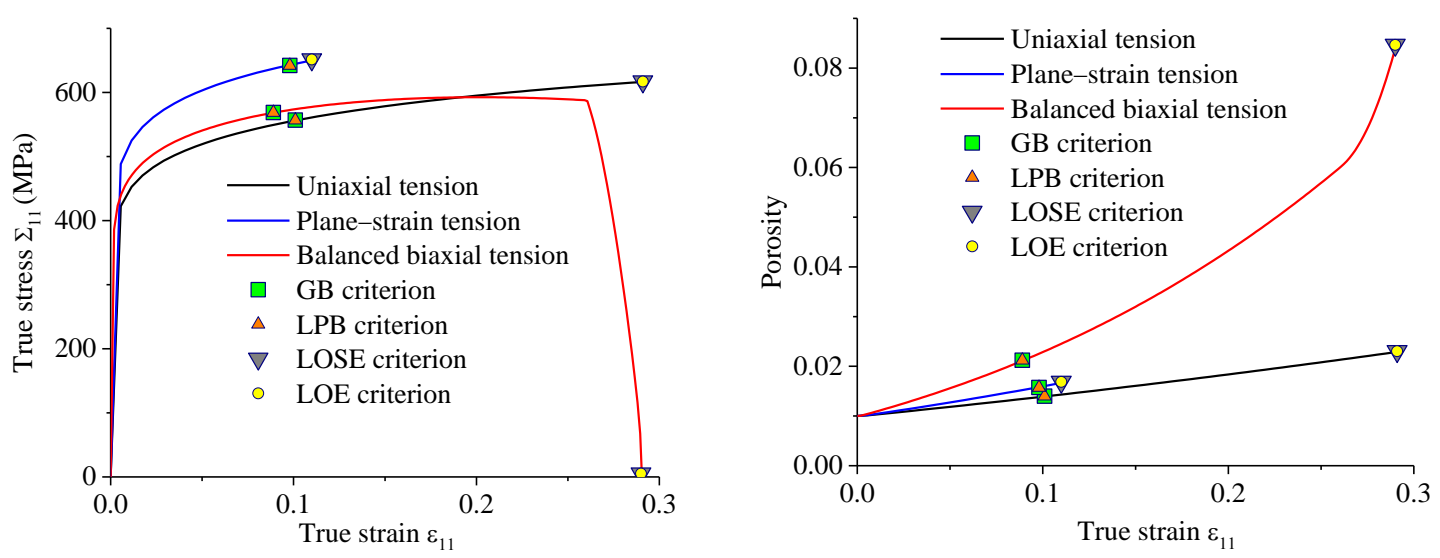

Fig. 10. True stress-strain curves (left) and porosity evolution (right), for material M1 under UT, PST and BBT, using the GTN damage model with strain-controlled nucleation and associative plasticity.

\subsection{Strain-controlled nucleation and non-associative plasticity}

In the present investigation, non-associative plasticity is coupled with the GTN damage model using the Hill'48 plastic anisotropy. The mathematical expressions for both the yield function and the plastic potential surface are the same, as discussed in Section 2 . However, the Hill'48 anisotropy coefficients are different for the two functions. Note that the plastic flow direction is normal to the plastic petential. In this case, the analytical elastic-plastic tangent modulus $\mathbf{C}^{\text {ep }}$ is non-symmetric (see Eq. (20)), with the following relation for tensor $\mathbf{M}$ :

$\mathbf{M}=\frac{\partial \Phi_{\mathrm{Y}}}{\partial \mathbf{\Sigma}}$

In this section, only one material is simulated, which corresponds to the fictitious material M1 used in the previous section (see Tables 6 and 8 for the elasto-plasticity and damage material parameters, respectively). The Hill' 48 anisotropy parameters for both the yield function and the plastic potential surface are reported in Table 7.

\section{Table 9}

Hill'48 anisotropy coefficients for non associative plasticity.

\begin{tabular}{cccccccccccc}
\hline$F_{\mathrm{Y}}$ & $G_{\overline{\mathrm{Y}}}$ & $H_{\mathrm{Y}}$ & $L_{\mathrm{Y}}$ & $M_{\mathrm{Y}}$ & $N_{\mathrm{Y}}$ & $F_{\mathrm{P}}$ & $G_{\overline{\mathrm{P}}}$ & $H_{\mathrm{P}}$ & $L_{\mathrm{P}}$ & $M_{\mathrm{P}}$ & $N_{\overline{\mathrm{P}}}$ \\
\hline 0.251 & 0.297 & 0.703 & 1.5 & 1.5 & 1.29 & 0.215 & 0.347 & 0.653 & 1.5 & 1.5 & 1.32 \\
\hline
\end{tabular}

The predicted FLDs using the non-associative GTN damage model with strain-controlled nucleation are shown in Fig. 11. In contrast to the previous predictions (i.e., using associative plasticity and strain-controlled nucleation), it can be observed that the consideration of nonassociative plasticity, which results in a non-symmetric analytical elastic-plastic tangent 
modulus, leads to the prediction of quite distinct necking limit strains for the four bifurcationbased instability criteria. More specifically, in the left-hand side of the FLDs, the lowest and highest ductility limits are predicted by GB criterion and LOE criterion, respectively. For the LOSE criterion, the latter appears to be more conservative than the LOE criterion, while the LPB criterion is less conservative than the GB theory. In the right-hand side of the FLDs, the order of prediction for diffuse necking is similar to that obtained in the left-hand side of the FLDs, while for both LOSE and LOE criteria, the same limit strains for localized necking are predicted. Overall, this hierarchical order of the predicted FLDs is well consistent with the theoretical classification (see Section 3.2).

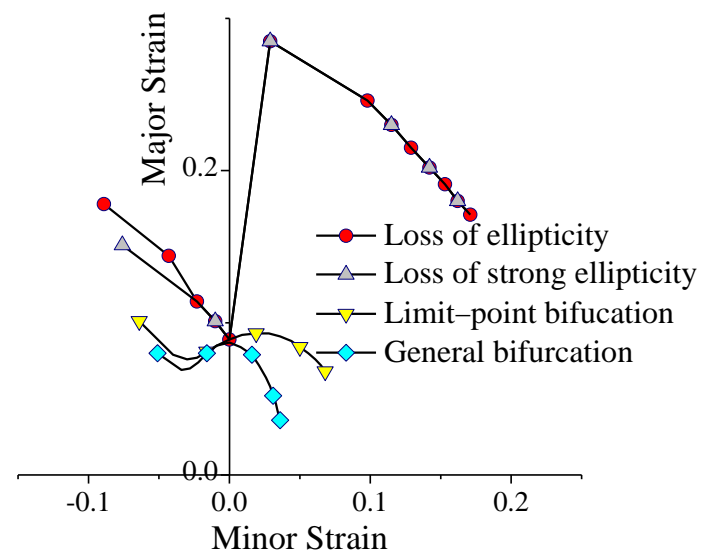

Fig. 11. FLDs predicted by the four bifurcation-based instability criteria coupled with the GTN damage model and strain-controlled nucleation. Case of non-associative plasticity.

Figure 12 compares the FLDs predicted by the AFR and NAFR GTN damage models with strain-controlled nucleation, which are combined with the four bifurcation criteria. It can be seen that the FLDs predicted by considering the NAFR GTN model are lower than those predicted by the AFR GTN model for all strain paths. The reason behind this observation is that the introduction of NAFR in the constitutive model brings more destabilizing effects, which promotes early occurrence of plastic instability. 


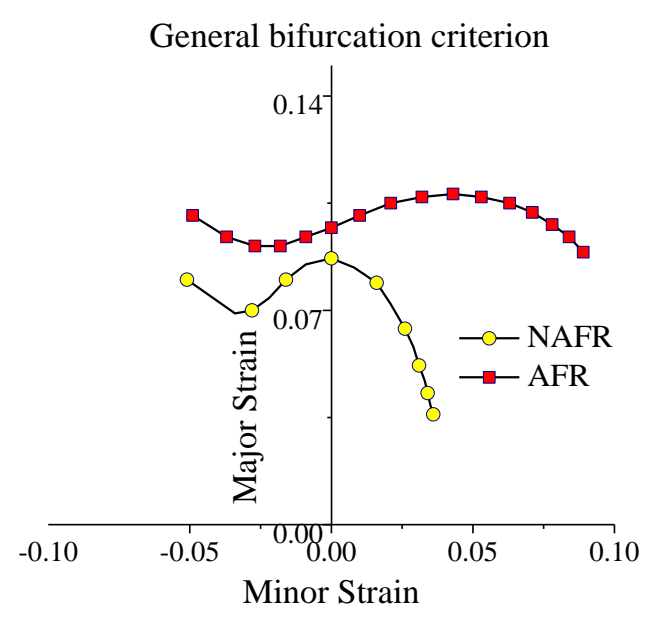

(a)

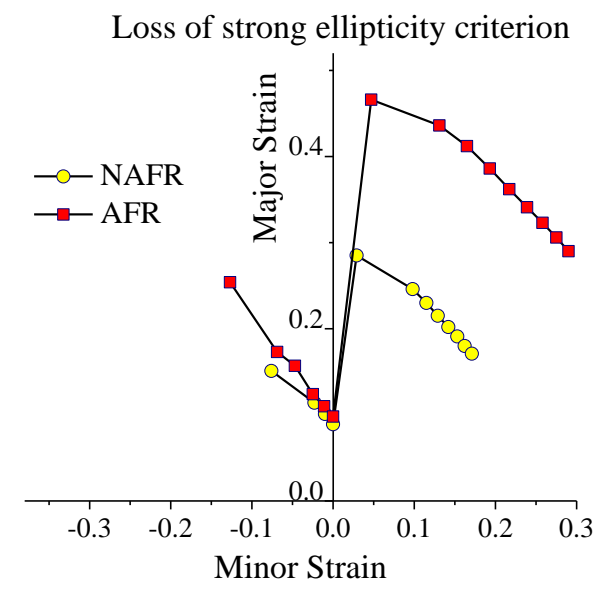

(c)

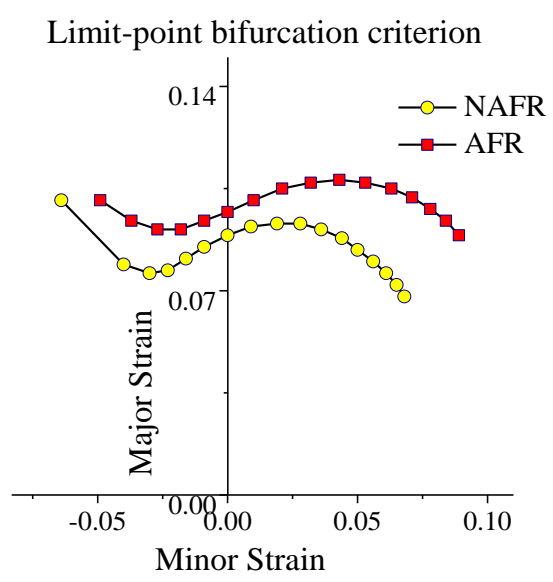

(b)

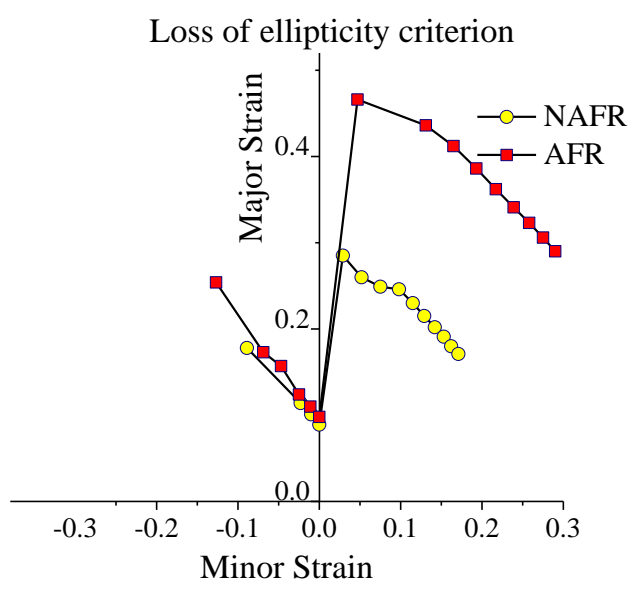

(d)

Fig. 12. Comparison of the FLDs predicted by the associative and non-associative GTN damage models with strain-controlled nucleation and (a) GB criterion, (b) LPB criterion, (c) LOSE criterion, and (d) LOE criterion.

As to the stress-strain curves and porosity evolution, Fig. 13 depicts the material responses for three typical strain paths: UT, PST and BBT. Results that are similar to the case of associative plasticity are observed, with the occurrence of localized necking in the positive hardening regime for the UT and PST loading paths, while for the BBT loading path, negative hardening modulus is required for localized necking. 

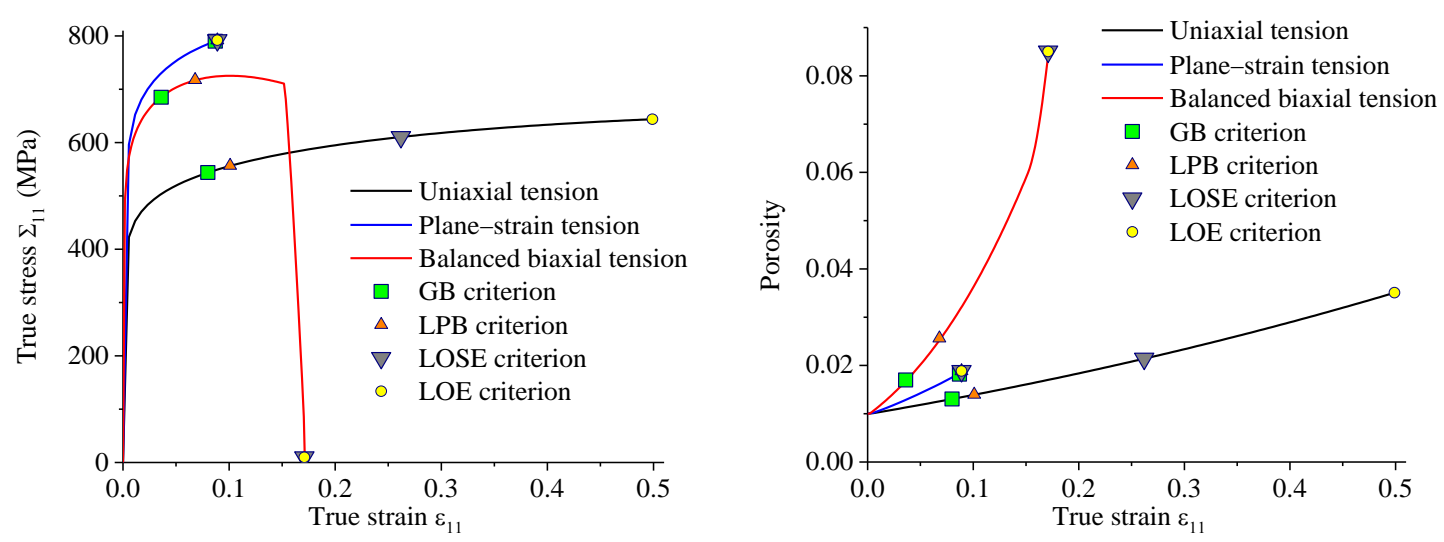

Fig. 13. True stress-strain curves (left) and porosity evolution (right), under UT, PST and BBT, using the GTN damage model with strain-controlled nucleation and non-associative plasticity.

\subsection{Stress-controlled nucleation and associative plasticity}

Unlike the previous section, where non-associative plasticity was considered to bring about significant destabilizing effect, the GTN damage model with stress-controlled nucleation and associative plasticity is considered in this section. In this case, the void nucleation amplitudes are $A_{N}=0$ and $B_{N}>0$. Note that the yield surface and the plastic potential are similar, i.e., $\Phi_{\mathrm{Y}}=\Phi_{\mathrm{P}}$. However, the stress-controlled nucleation leads to some sort of non-normality in the plastic flow, which results in a non-symmetric analytical elastic-plastic tangent modulus $\mathbf{C}^{\mathrm{ep}}$ (see Eq. (20)). The GTN damage parameters for the fictitious material used in the simulations are summarized in Table 9.

Table 9

GTN damage parameters for stress-controlled nucleation.

\begin{tabular}{ccccccccc}
\hline$f_{0}$ & $f_{N}$ & $\sigma_{N}(\mathrm{MPa})$ & $s_{N}$ & $\mathrm{q}_{1}$ & $\mathrm{q}_{2}$ & $\mathrm{q}_{3}$ & $f_{c r}$ & $\delta_{G T N}$ \\
\hline 0.01 & 0.1 & 850 & 1.5 & 1.5 & 1 & 2.15 & 0.0601 & 20 \\
\hline
\end{tabular}

Figure 14 depicts the FLDs predicted by the four bifurcation-based instability criteria, where four distinct FLDs are obtained. Indeed, in contrast to the first studied case of straincontrolled nucleation and associative plasticity, the predicted limit strains are well distinct in the left-hand side of the FLDs, for diffuse necking criteria (i.e., GB and LPB) as well as for localized necking criteria (i.e., LOSE and LOE). However, in the right-hand side of the FLDs, the limit strains coincide for both localized necking criteria, which has been also observed in the case of strain-controlled nucleation and asseciative plasticity. Note that the GB and LPB criteria predict the occurrence of diffuse necking at different limit strains for all of the strain paths considered, except for the BBT strain path loading, where the limit strains coincide for both diffuse necking criteria. On the whole, as for the previous two cases in Sections 4.2 and 4.3, the hierarchical order of the FLDs is well respected with regard to the established theoretical one. 


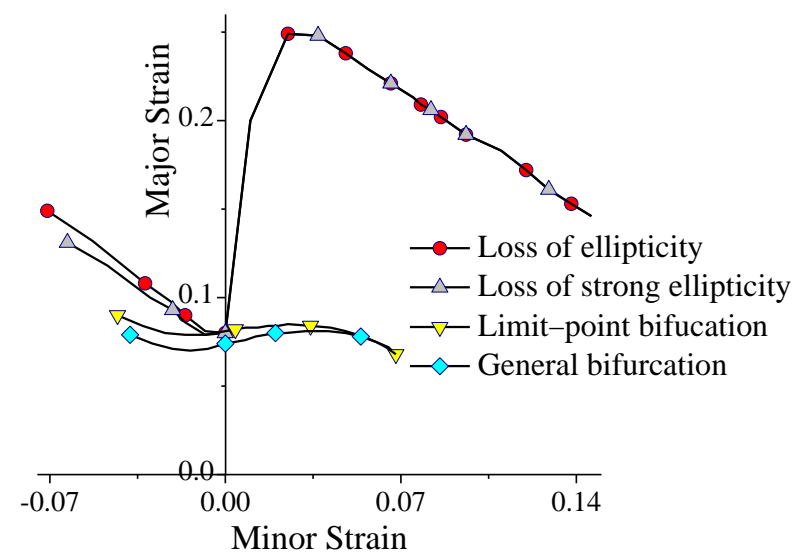

Fig. 14. FLDs predicted by the four bifurcation-based instability criteria coupled with the GTN damage model and stress-controlled nucleation. Case of associative plasticity.

In order to provide better insight into the plastic instability phenomena for the four bifurcation theories, Fig. 15 exhibits the logarithmic plots for minimum values of determinants of the acoustic tensor $\mathbf{Q}$, tangent modulus $\mathbf{L}^{\mathrm{B}}$, and their symmetric parts $\left(\mathbf{Q}^{\text {sym }}\right.$ and $\mathbf{L}^{\mathrm{B}^{\text {sym }}}$, respectively), for three typical strain loading paths i.e., UT, PST, and BBT. The non-bifurcation condition according to the GB criterion requires all the eigenvalues of the symmetric part of the tangent modulus $\mathbf{L}^{\mathrm{B}^{\text {sym }}}$ to be positive. This condition amounts here to the positiveness of the determinant of the tangent modulus $\mathbf{L}^{\mathrm{B} \text { sym }}$. Similarly, the non-localization condition given by the LOSE criterion requires positive definiteness of the acoustic tensor $\mathbf{Q}$, which implies that, for a non-localization state, det $\mathbf{Q}^{\text {sym }}>0$. Recalling also that LPB and LOE predict diffuse and localized necking, respectively, when $\operatorname{det} \mathbf{L}^{\mathrm{B}}=0$ and $\operatorname{det} \mathbf{Q}=0$. Therefore, the different bifurcation criteria predict plastic instability when their associated minimum determinant of the tensor quantity, as discussed above, tends to zero (see Fig. 15).

It is interesting to note that, when the tangent modulus $\mathbf{L}^{\mathrm{B}}$ is symmetric, or when the nonsymmetric part is negligibly small, then $\mathbf{L}^{\mathrm{B}} \approx \mathbf{L}^{\mathrm{B}^{\text {sym }}}$ and $\mathbf{Q} \approx \mathbf{Q}^{\text {sym }}$. In this case, the $\mathrm{GB}$ and the LOSE criteria become equivalent to the LPB and the LOE criteria, respectively (see Fig. 9). However, in Fig. 15, since the tangent modulus $\mathbf{L}^{\mathrm{B}}$ is non-symmetric, it can be clearly seen that the occurrence of plastic instabilities with the GB and the LOSE criteria can be predicted earlier than the LPB and the LOE criteria, respectively. 


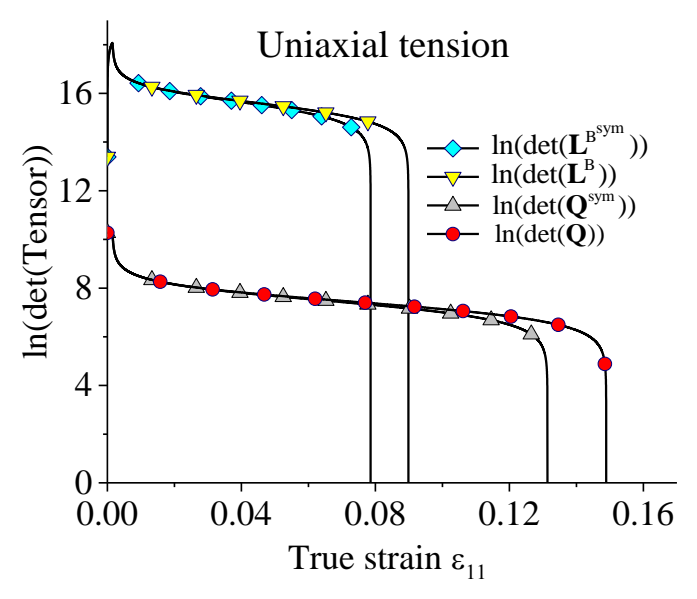

(a)

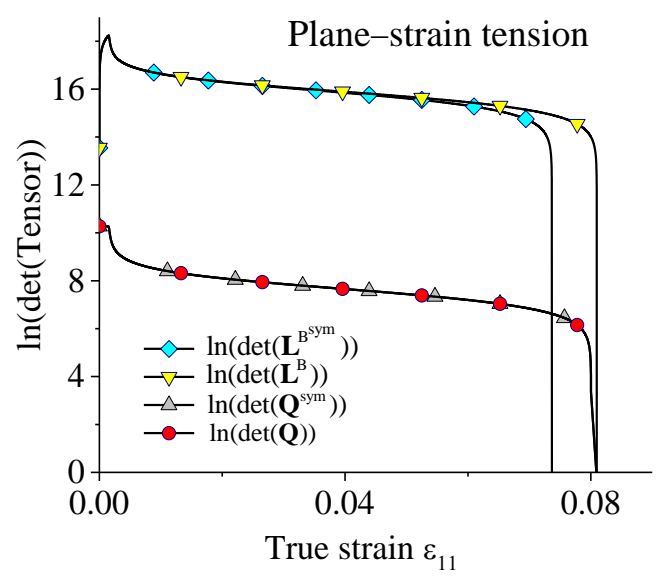

(b)

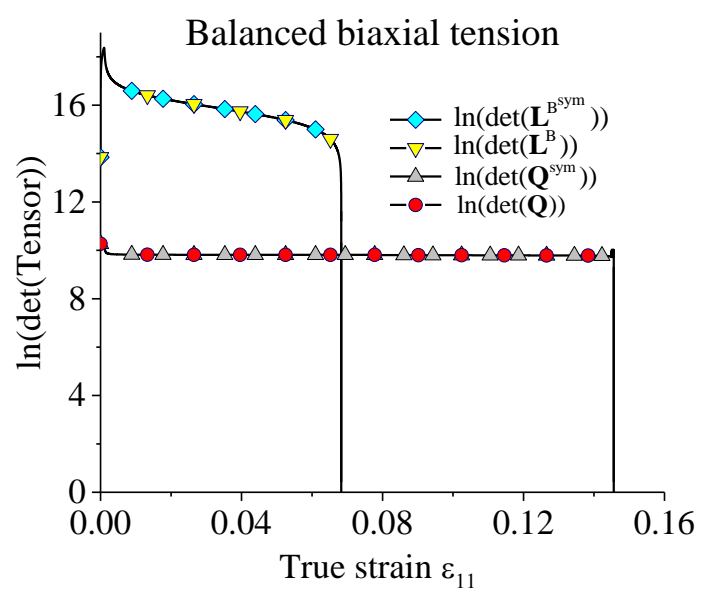

(c)

Fig. 15. Logarithmic plots of minimum determinants of the tangent modulus $\mathbf{L}^{\mathrm{B}}$, acoustic tensor $\mathbf{Q}$, and their symmetric parts $\left(\mathbf{L}^{\mathrm{B}}{ }^{\mathrm{sym}}\right.$ and $\mathbf{Q}^{\mathrm{sym}}$ ) for (a) uniaxial tension, (b) plane-strain tension, and (c) balanced biaxial tension.

\subsection{Stress-controlled nucleation and non-associative plasticity}

In this section, two destabilizing mechanisms are combined simultaneously within the constitutive equations, i.e., non-associative plasticity and stress-controlled nucleation, which induce some sort of non-normality in the plastic flow. More specifically, the anisotropic GTN damage model with stress-controlled nucleation is coupled with the four bifurcation theories for the prediction of FLDs. Moreover, the yield surface and the plastic potential are different with regard to the Hill' 48 anisotropy coefficients. The anisotropy coefficients for the yield surface and the plastic potential as well as the GTN damage parameters used in the simulations are those used in the previous sections (see Tables 7 and 9). The FLDs predicted by the resulting approach 
are shown in Fig. 16. In the left-hand side of the FLDs, the consideration of both mechanisms, i.e., non-associative plasticity and stress-controlled nucleation, seems not to destabilize the prediction of diffuse and localized necking, as in the case of associative plasticity and straincontrolled nucleation (see Fig. 9). However, in the right-hand side of the FLDs, these destabilizing mechanisms lead to distinct limit strains for diffuse necking criteria (i.e., GB and LPB). Similar to the previous combinations of destabilizing mechanisms, the hierarchical order of prediction of FLDs, in this case, is once again well consistent with regard to the established theoretical one (see Section 3.2).

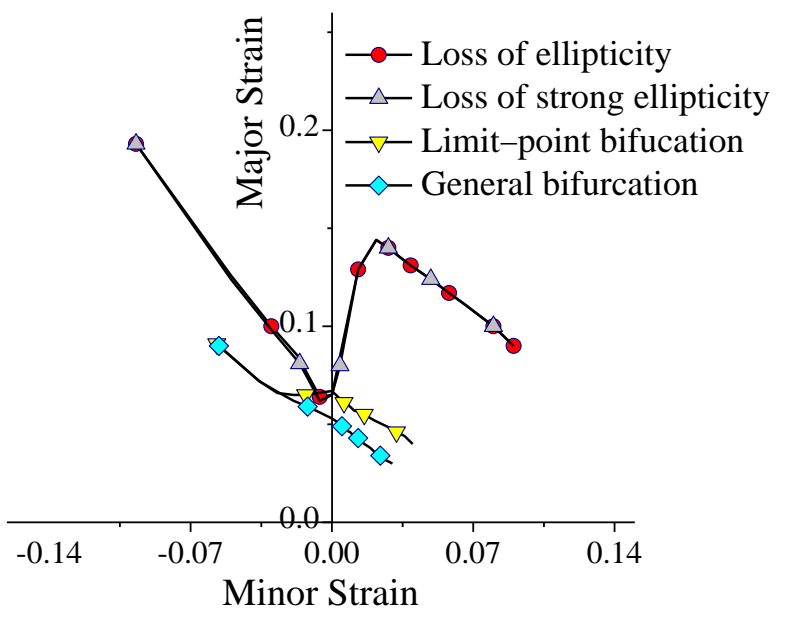

Fig. 16. FLDs predicted by the four bifurcation-based instability criteria coupled with the GTN damage model and stress-controlled nucleation. Case of non-associative plasticity.

\subsection{Orientation of the localization band}

The orientation of the localization band, as predicted by LOSE and LOE criteria, is investigated in this section. Note that the band orientation is only defined by a single in-plane angle, since the framework of plane-stress conditions is adopted in this work (see Fig. 5). Fig. 17 shows the orientations of the localization bands, as predicted by LOSE and LOE criteria for different values of the strain-path ratio. The localization band orientations are also compared with the analytical band orientations given by the Hill'52 localized necking criterion [62]. For the considered variants of the GTN model, it can be seen that the predicted localization band orientations are in excellent agreement with the Hill'52 analytical formula (i.e., $\theta=\tan ^{-1} \sqrt{-\rho}$, where $\rho$ is the strain-path ratio), for both LOSE and LOE criteria. It is worth noting that because the Hill' 52 criterion is only applicable to the left-hand side of the FLD, the comparison in the range of positive biaxial stretching (i.e., $\rho>0$ ) only involves the LOSE and LOE criteria, which predict equivalent band orientations. 


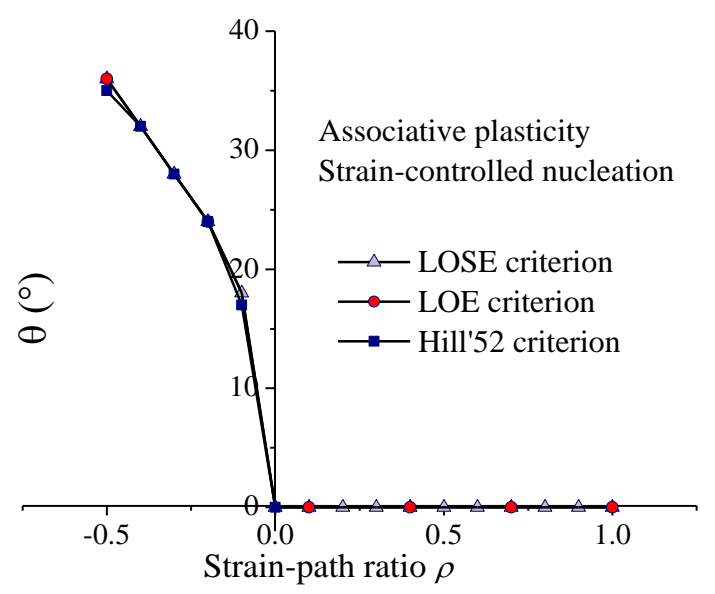

(a)

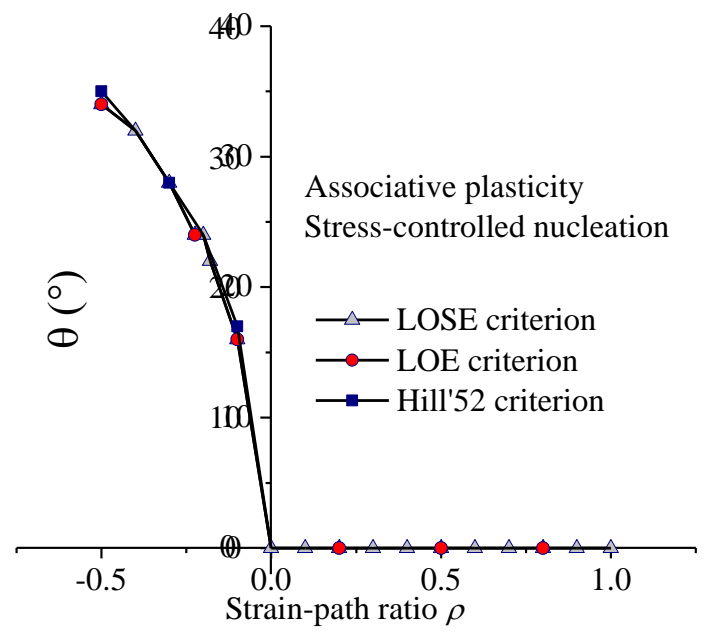

(c)

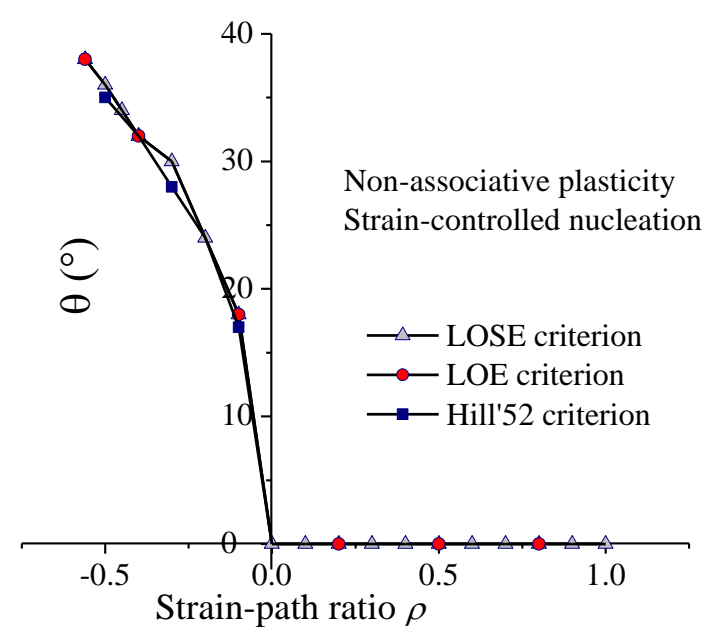

(b)

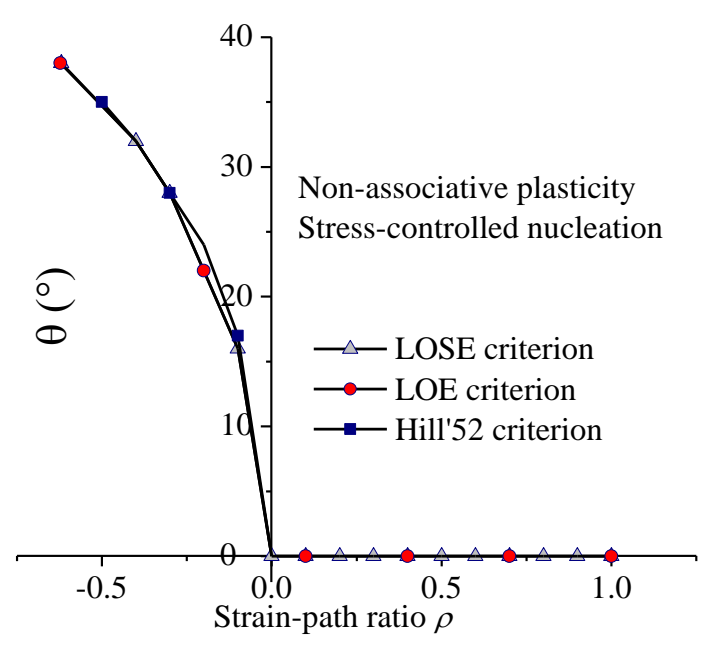

(d)

Fig. 17. Orientations of the localization bands, predicted with the LOSE, LOE and Hill' 52 localized necking criteria.

\section{Conclusions}

In the present investigation, the widely-used GTN damage model has been coupled with four bifurcation-based plastic instability criteria for the prediction of forming limit diagrams. Two of these plastic instability criteria, i.e., general bifurcation criterion (GB) and limit-point bifurcation criterion (LPB), predict diffuse necking; whereas the two others, i.e., loss of strong ellipticity criterion (LOSE) and loss of ellipticity criterion (LOE), predict localized necking. The constitutive equations together with the four plastic instability criteria have been implemented into the finite element code ABAQUS/standard via user-defined material behavior (UMAT) and user-defined output variables (UVARM) subroutines. The constitutive equations have been formulated in a fully three-dimensional framework; however, plane-stress conditions have been 
considered while applying the plastic instability criteria, since the intended application of the present contribution is the prediction of ductility limits in thin sheet metals. Various linear strain loading paths, corresponding to in-plane biaxial stretching, have been applied on a single finite element so that all structural (geometric) instabilities are excluded. These strain loading paths cover different loading conditions, including uniaxial tension, plane-strain tension, and balanced biaxial tension, for the purpose of predicting FLDs.

Theoretical classification of the four bifurcation-based plastic instability criteria has been established, from which it appears that the theoretical lower bound for the prediction of necking is provided by the GB criterion and the theoretical upper bound is provided by the LOE criterion. As to the LPB criterion, the latter is less conservative than the GB criterion, while the LOSE criterion is more conservative than the LOE criterion.

In this contribution, two destabilizing mechanisms have been introduced within the constitutive equations, i.e., non-associative plasticity and stress-controlled nucleation inducing some sort of non-normality in the plastic flow. To this end, the Hill' 48 anisotropic model, with different sets of anisotropy coefficients for the yield surface and the plastic potential, has been coupled with the GTN damage model. Non-symmetry in the analytical elastic-plastic tangent modulus has also been introduced by considering stress-controlled nucleation, for which the nucleation amplitude depends on the mean Cauchy stress.

First, the FLDs have been predicted by the GTN damage model with strain-controlled nucleation and associative plasticity. The analytical elastic-plastic tangent modulus is symmetric in this case, while the localization tangent modulus is non-symmetric due to the large strain framework. In this case, the GB and the LPB criteria predict the same critical strains for diffuse necking, while the LOSE and LOE criteria predict the same limit strains for localized necking. Then, non-associative plasticity is considered, which results in a non-symmetric analytical elastic-plastic tangent modulus. For this case, the GB criterion predicts limit strains lower than those obtained with the LPB criterion for all of the strain loading paths considered. As to localized necking, the LOSE criterion predicts limit strains lower than the LOE criterion only for the left-hand side of the FLD, while both LOSE and LOE predictions coincide for the right-hand side of the FLD. Similar destabilizing effects on diffuse and localized necking have also been observed when considering stress-controlled nucleation and non-associative plasticity. Throughout all studied cases, the hierarchical order of the predicted FLDs has been shown to be consistent with the preliminarily established theoretical classification, which states that the GB criterion is a lower bound to all the bifurcation criteria, in terms of necking prediction, while the LOE criterion provides an upper bound.

\section{References}

[1] Keeler SP, Backofen WA. Plastic instability and fracture in sheet stretched over rigid punches. ASM Transactions Quarterly 1963;56(11):25-48. 
[2] Goodwin GM. Application of strain analysis to sheet metal forming problems in the press shop. SAE Transactions 1968;380-7.

[3] Nakazima K, Kikuma T, Hasuka K. Study on the formability of steel sheets. Yawata Technical Reports 1968;264:8517-8530.

[4] Hecker SS. A cup test for assessing stretchability. Metal Eng. Quart 1974; 14:30-36.

[5] Basak S, Panda SK, Zhou YN. Formability assessment of pre strained automotive grade steel sheets using stress based and polar effective plastic strain-forming limit diagram. Journal of Engineering Materials and Technology 2015;137(4).

[6] Kachanov LM. On creep rupture time. Izv. Acad. Nauk SSSR, Otd. Techn. Nauk 1958;8:26-31.

[7] Lemaitre J. A Course on Damage Mechanics. Springer Science \& Business Media 1992.

[8] Voyiadjis GZ, Kattan PI. Advances in damage mechanics: metals and metal matrix composites. Elsevier 1999.

[9] Hambli R. Comparison between Lemaitre and Gurson damage models in crack growth simulation during blanking process. International Journal of Mechanical Sciences 2001;43(12):2769-90.

[10] Brünig M. Numerical analysis and elastic-plastic deformation behavior of anisotropically damaged solids. International Journal of Plasticity 2002;18(9):1237-70.

[11] Menzel A, Ekh M, Runesson K, Steinmann P. A framework for multiplicative elastoplasticity with kinematic hardening coupled to anisotropic damage. International Journal of Plasticity 2005;21(3):397-434.

[12] Lee SW, Pourboghrat F. Finite element simulation of the punchless piercing process with Lemaitre damage model. International Journal of Mechanical Sciences 2005;47(11):175668.

[13] Bouchard PO, Bourgeon L, Fayolle S, Mocellin K. An enhanced Lemaitre model formulation for materials processing damage computation. International Journal of Material Forming 2011;4(3):299-315.

[14] Doghri I. Mechanics of deformable solids: linear, nonlinear, analytical and computational aspects. Springer Science \& Business Media 2013.

[15] Lian J, Feng Y, Münstermann S. A modified Lemaitre damage model phenomenologically accounting for the Lode angle effect on ductile fracture. Procedia Materials Science 2014;3:1841-7.

[16] Li H, Yang H, Lu RD, Fu MW. Coupled modeling of anisotropy variation and damage evolution for high strength steel tubular materials. International Journal of Mechanical Sciences 2016;105:41-57.

[17] Gurson AL. Continuum theory of ductile rupture by void nucleation and growth: Part IYield criteria and flow rules for porous ductile media. Journal of Engineering Materials and Technology 1977;99(1):2-15.

[18] Tvergaard V. Influence of voids on shear band instabilities under plane strain conditions. International Journal of Fracture 1981;17(4):389-407. 
[19] Tvergaard V. Material failure by void coalescence in localized shear bands. International Journal of Solids and Structures 1982;18(8):659-72.

[20] Tvergaard V. On localization in ductile materials containing spherical voids. International Journal of Fracture 1982;18(4):237-52.

[21] Chu CC, Needleman A. Void nucleation effects in biaxially stretched sheets. Journal of Engineering Materials and Technology 1980;102:249-256.

[22] Tvergaard V, Needleman A. Analysis of the cup-cone fracture in a round tensile bar. Acta Metallurgica 1984;32(1):157-69.

[23] Gologanu M, Leblond JB, Devaux J. Approximate models for ductile metals containing non-spherical voids - case of axisymmetric prolate ellipsoidal cavities. Journal of the Mechanics and Physics of Solids 1993;41(11):1723-54.

[24] Gologanu M, Leblond JB, Devaux J. Approximate models for ductile metals containing nonspherical voids - case of axisymmetric oblate ellipsoidal cavities. Journal of Engineering Materials and Technology 1994;116(3):290-7.

[25] Klöcker H, Tvergaard V. Growth and coalescence of non-spherical voids in metals deformed at elevated temperature. International Journal of Mechanical Sciences 2003;45(8):1283-308.

[26] Madou K, Leblond JB. A Gurson-type criterion for porous ductile solids containing arbitrary ellipsoidal voids-I: Limit-analysis of some representative cell. Journal of the Mechanics and Physics of Solids 2012;60(5):1020-36.

[27] Madou K, Leblond JB. A Gurson-type criterion for porous ductile solids containing arbitrary ellipsoidal voids-II: Determination of yield criterion parameters. Journal of the Mechanics and Physics of Solids 2012;60(5):1037-58.

[28] Madou K, Leblond JB. Numerical studies of porous ductile materials containing arbitrary ellipsoidal voids-I: Yield surfaces of representative cells. European Journal of MechanicsA/Solids 2013;42:480-9.

[29] Madou K, Leblond JB, Morin L. Numerical studies of porous ductile materials containing arbitrary ellipsoidal voids-II: Evolution of the length and orientation of the void axes. European Journal of Mechanics-A/Solids 2013;42:490-507.

[30] Xue L. Constitutive modeling of void shearing effect in ductile fracture of porous materials. Engineering Fracture Mechanics 2008;75(11):3343-66.

[31] Nahshon K, Hutchinson JW. Modification of the Gurson model for shear failure. European Journal of Mechanics-A/Solids 2008;27(1):1-17.

[32] Zhou J, Gao X, Sobotka JC, Webler BA, Cockeram BV. On the extension of the Gursontype porous plasticity models for prediction of ductile fracture under shear-dominated conditions. International Journal of Solids and Structures 2014;51(18):3273-91.

[33] Dæhli LE, Morin D, Børvik T, Hopperstad OS. A Lode-dependent Gurson model motivated by unit cell analyses. Engineering Fracture Mechanics 2018;190:299-318. 
[34] Wang X, Dong X. A void evolution model accounting for stress triaxiality, Lode parameter and effective strain for hot metal forming. International Journal of Mechanical Sciences 2020;168:105309.

[35] Dormieux L, Kondo D. An extension of Gurson model incorporating interface stresses effects. International Journal of Engineering Science 2010;48(6):575-81.

[36] Morin L, Kondo D, Leblond JB. Numerical assessment, implementation and application of an extended Gurson model accounting for void size effects. European Journal of Mechanics-A/Solids 2015;51:183-92.

[37] Lacroix R, Leblond JB, Perrin G. Numerical study and theoretical modelling of void growth in porous ductile materials subjected to cyclic loadings. European Journal of Mechanics-A/Solids 2016;55:100-9.

[38] Morin L, Michel JC, Leblond JB. A Gurson-type layer model for ductile porous solids with isotropic and kinematic hardening. International Journal of Solids and Structures 2017;118:167-78.

[39] Monchiet V, Cazacu O, Charkaluk E, Kondo D. Macroscopic yield criteria for plastic anisotropic materials containing spheroidal voids. International Journal of Plasticity 2008;24(7):1158-89.

[40] Morin L, Madou K, Leblond JB, Kondo D. A new technique for finite element limitanalysis of Hill materials, with an application to the assessment of criteria for anisotropic plastic porous solids. International Journal of Engineering Science 2014;74:65-79.

[41] Hill R. A theory of the yielding and plastic flow of anisotropic metals. Proceedings of the Royal Society of London. Series A. Mathematical and Physical Sciences 1948;193(1033):281-97.

[42] Karafillis AP, Boyce MC. A general anisotropic yield criterion using bounds and a transformation weighting tensor. Journal of the Mechanics and Physics of Solids 1993;41(12):1859-86.

[43] Bron F, Besson J. A yield function for anisotropic materials application to aluminum alloys. International Journal of Plasticity 2004;20(4-5):937-63.

[44] Barlat F, Aretz H, Yoon JW, Karabin ME, Brem JC, Dick RE. Linear transformation-based anisotropic yield functions. International Journal of Plasticity 2005;21(5):1009-39.

[45] Aretz H, Barlat F. New convex yield functions for orthotropic metal plasticity. International Journal of Non-Linear Mechanics 2013;51:97-111.

[46] Banabic D, Aretz H, Comsa DS, Paraianu L. An improved analytical description of orthotropy in metallic sheets. International Journal of Plasticity 2005;21(3):493-512.

[47] Cai Z, Wan M, Liu Z, Wu X, Ma B. Approximate method formulating plastic potentials of porous sheet metals with non-quadratic anisotropy. International Journal of Mechanical Sciences 2017;123:198-213.

[48] Cazacu O. New yield criteria for isotropic and textured metallic materials. International Journal of Solids and Structures 2018;139:200-10.

[49] Bassani JL. Plastic flow of crystals. Advances in Applied Mechanics 1994;30:192-259. 
[50] Racherla V, Bassani JL. Strain burst phenomena in the necking of a sheet that deforms by non-associated plastic flow. Modelling and Simulation in Materials Science and Engineering 2006;15(1):S297.

[51] Spitzig WA, Richmond O. The effect of pressure on the flow stress of metals. Acta Metallurgica 1984;32(3):457-63.

[52] Lademo OG, Hopperstad OS, Langseth M. An evaluation of yield criteria and flow rules for aluminium alloys. International Journal of Plasticity 1999;15(2):191-208.

[53] Mohr D, Dunand M, Kim KH. Evaluation of associated and non-associated quadratic plasticity models for advanced high strength steel sheets under multi-axial loading. International Journal of Plasticity 2010;26(7):939-56.

[54] Gao X, Zhang T, Zhou J, Graham SM, Hayden M, Roe C. On stress-state dependent plasticity modeling: Significance of the hydrostatic stress, the third invariant of stress deviator and the non-associated flow rule. International Journal of Plasticity 2011;27(2):217-31.

[55] Stoughton TB. A non-associated flow rule for sheet metal forming. International Journal of Plasticity 2002;18(5-6):687-714.

[56] Lian J, Shen F, Jia X, Ahn DC, Chae DC, Münstermann S, Bleck W. An evolving nonassociated Hill48 plasticity model accounting for anisotropic hardening and r-value evolution and its application to forming limit prediction. International Journal of Solids and Structures 2018;151:20-44.

[57] Ghorbel O, Koubaa S, Mars J, Wali M, Dammak F. Non associated-anisotropic plasticity model fully coupled with isotropic ductile damage for sheet metal forming applications. International Journal of Solids and Structures 2019;166:96-111.

[58] Shen F, Münstermann S, Lian J. Forming limit prediction by the Marciniak-Kuczynski model coupled with the evolving non-associated Hill48 plasticity model. Journal of Materials Processing Technology 2019:116384.

[59] Tang B, Wu F, Wang Z, Zhang S. Study on non-associated plasticity with various forward Euler stress integration algorithms and its prediction of earing in cylindrical cup drawing. International Journal of Mechanical Sciences 2019;157:384-402.

[60] Considère M. Memoire sur l'emploi du fer et de l'acier dans les constructions. Ann. Ponts et Chaussées 1885;9:574-775.

[61] Swift H. Plastic instability under plane stress. Journal of the Mechanics and Physics of Solids 1952;1(1):1-8.

[62] Hill R. On discontinuous plastic states, with special reference to localized necking in thin sheets. Journal of the Mechanics and Physics of Solids 1952;1(1):19-30.

[63] Hora P, Tong L, Reissner J. A prediction method for ductile sheet metal failure in FEsimulation. In Proceedings of NUMISHEET 1996;96:252-56.

[64] Mattiasson K, Sigvant M, Larson M. Methods for forming limit prediction in ductile metal sheets. In Proceedings of IDDRG 2006;6:1-9. 
[65] Marciniak Z, Kuczyński K. Limit strains in the processes of stretch-forming sheet metal. International Journal of Mechanical Sciences 1967;9(9):609-20.

[66] Hutchinson JW, Neale KW. Sheet necking-II. Time-independent behavior. In Mechanics of sheet metal forming. Springer, Boston, MA 1978:127-153.

[67] Yamamoto H. Conditions for shear localization in the ductile fracture of void-containing materials. International Journal of Fracture 1978;14(4):347-65.

[68] Drucker DC. On uniqueness in the theory of plasticity. Quarterly of Applied Mathematics 1956;14(1):35-42.

[69] Hill R. A general theory of uniqueness and stability in elastic-plastic solids. Journal of the Mechanics and Physics of Solids 1958;6(3):236-49.

[70] Valanis KC. Banding and stability in plastic materials. Acta Mechanica 1989;79(1-2):11341.

[71] Rudnicki JW, Rice JR. Conditions for the localization of deformation in pressure-sensitive dilatant materials. Journal of the Mechanics and Physics of Solids 1975;23(6):371-94.

[72] Stören S, Rice JR. Localized necking in thin sheets. Journal of the Mechanics and Physics of Solids 1975;23(6):421-41.

[73] Rice JR. Localization of plastic deformation. In: Koiter (Ed.), Theoretical and Applied Mechanics 1976;1:207-20.

[74] Bigoni D, Hueckel T. Uniqueness and localization-I. Associative and non-associative elastoplasticity. International Journal of Solids and structures 1991;28(2):197-213.

[75] Neilsen MK, Schreyer HL. Bifurcations in elastic-plastic materials. International Journal of Solids and Structures 1993;30(4):521-44.

[76] Rizzi E, Loret B. Qualitative analysis of strain localization. Part I: Transversely isotropic elasticity and isotropic plasticity. International journal of plasticity 1997;13(5):461-99.

[77] Loret B, Rizzi E. Anisotropic stiffness degradation triggers onset of strain localization. International Journal of Plasticity 1997;13(5):447-59.

[78] Loret B, Rizzi E. Qualitative analysis of strain localization. Part II: Transversely isotropic elasticity and plasticity. International Journal of Plasticity 1997;13(5):501-19.

[79] Benallal A, Billardon R, Geymonat G. Bifurcation and localization in rate-independent materials. Some general considerations. In Bifurcation and stability of dissipative systems. Springer, Vienna 1993:1-44.

[80] Mansouri LZ, Chalal H, Abed-Meraim F. Ductility limit prediction using a GTN damage model coupled with localization bifurcation analysis. Mechanics of Materials 2014;76:6492.

[81] Chalal H, Abed-Meraim F. Hardening effects on strain localization predictions in porous ductile materials using the bifurcation approach. Mechanics of Materials 2015;91:152-66.

[82] Bouktir Y, Chalal H, Abed-Meraim F. Prediction of necking in thin sheet metals using an elastic-plastic model coupled with ductile damage and bifurcation criteria. International Journal of Damage Mechanics 2018;27(6):801-39. 
[83] Needleman A, Rice JR. Limits to ductility set by plastic flow localization. In Mechanics of sheet metal forming. Springer, Boston, MA 1978:237-267.

[84] Tvergaard V. Effect of yield surface curvature and void nucleation on plastic flow localization. Journal of the Mechanics and Physics of Solids 1987;35(1):43-60.

[85] Neto DM, Martins JM, Cunha PM, Alves JL, Oliveira MC, Laurent H, Menezes LF. Thermo-mechanical finite element analysis of the AA5086 alloy under warm forming conditions. International Journal of Solids and Structures 2018;151:99-117.

[86] Abed-Meraim F, Balan T, Altmeyer G. Investigation and comparative analysis of plastic instability criteria: application to forming limit diagrams. International Journal of Advanced Manufacturing Technology 2014;71(5-8):1247-62.

[87] Bigoni D, Zaccaria D. Loss of strong ellipticity in non-associative elastoplasticity. Journal of the Mechanics and Physics of Solids 1992;40(6):1313-31.

[88] Bigoni D. On smooth bifurcations in non-associative elastoplasticity. Journal of the Mechanics and Physics of Solids 1996;44(8):1337-51.

[89] Abed-Meraim F. Quelques problèmes de stabilité et de bifurcation des solides visqueux. $\mathrm{PhD}$ Thesis, Ecole Polytechnique, Palaiseau, France. 1999. 